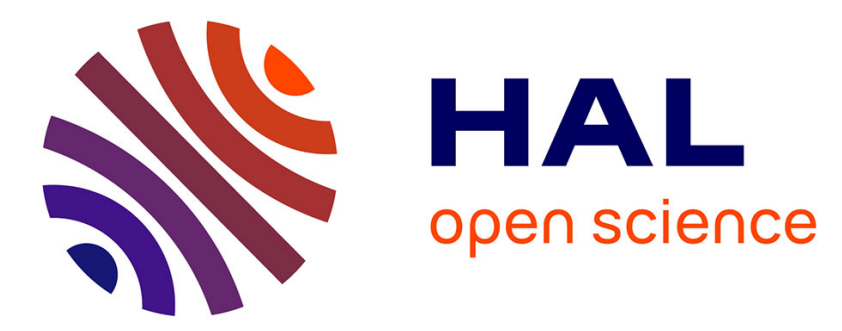

\title{
Experimental Investigation of Asymmetric Spinnaker Aerodynamics Using Pressure and Sail Shape Measurements
}

D. Motta, R.G.J Flay, P.J Richards, D.J Le Pelley, Julien Deparday, Patrick Bot

\section{To cite this version:}

D. Motta, R.G.J Flay, P.J Richards, D.J Le Pelley, Julien Deparday, et al.. Experimental Investigation of Asymmetric Spinnaker Aerodynamics Using Pressure and Sail Shape Measurements. Ocean Engineering, 2014, a paraitre. 10.1016/j.oceaneng.2014.07.023 . hal-01071557

\section{HAL Id: hal-01071557 https://hal.science/hal-01071557}

Submitted on 8 Oct 2014

HAL is a multi-disciplinary open access archive for the deposit and dissemination of scientific research documents, whether they are published or not. The documents may come from teaching and research institutions in France or abroad, or from public or private research centers.
L'archive ouverte pluridisciplinaire HAL, est destinée au dépôt et à la diffusion de documents scientifiques de niveau recherche, publiés ou non, émanant des établissements d'enseignement et de recherche français ou étrangers, des laboratoires publics ou privés. 


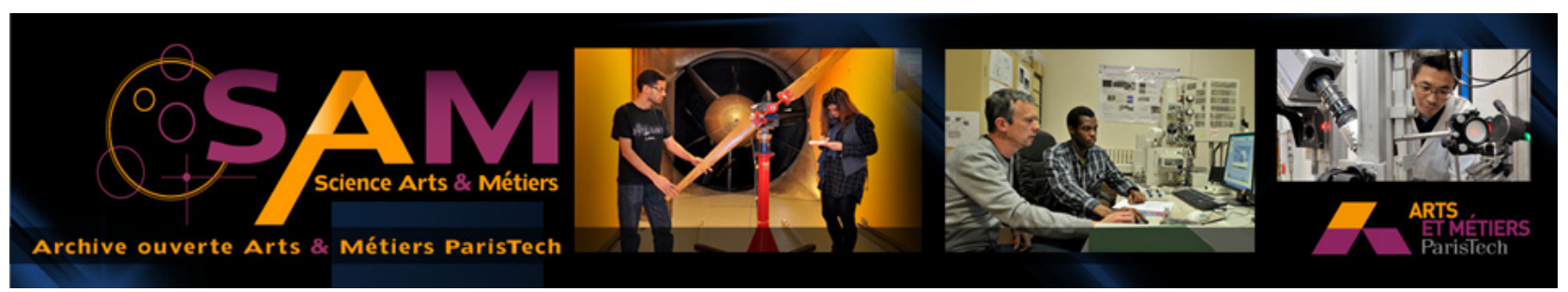

\section{Science Arts \& Métiers (SAM)}

is an open access repository that collects the work of Arts et Métiers ParisTech researchers and makes it freely available over the web where possible.

This is an author-deposited version published in: http://sam.ensam.eu

Handle ID: .http://hdl.handle.net/10985/8690

\section{To cite this version :}

D MOTTA, R.G.J. FLAY, P.J. RICHARDS, D.J. LE PELLEY, Julien DEPARDAY, Patrick BOT Experimental Investigation of Asymmetric Spinnaker Aerodynamics Using Pressure and Sail Shape Measurements - Ocean Engineering p.a paraitre - 2014 


\title{
Experimental Investigation of Asymmetric Spinnaker Aerodynamics Using Pressure and Sail Shape Measurements
}

\author{
D. Motta, Yacht Research Unit, University of Auckland, New Zealand, dmot267@aucklanduni.ac.nz \\ R.G.J. Flay, Yacht Research Unit, University of Auckland, New Zealand, r.flay@auckland.ac.nz \\ P.J. Richards, Yacht Research Unit, University of Auckland, New Zealand, pj.richards@auckland.ac.nz \\ D.J. Le Pelley, Yacht Research Unit, University of Auckland, New Zealand, d.lepelley@auckland.ac.nz \\ J. Deparday, Naval Academy Research Institute, France, julien.deparday@ecole-navale.fr \\ P. Bot, Naval Academy Research Institute, France, patrick.bot@ecole-navale.fr
}

\begin{abstract}
An innovative method combining simultaneous on-water pressure and sail shape measurements for determining aerodynamic forces produced by sails is described and used on Stewart 34 and J80 Class yachts flying asymmetric spinnakers. Data were recorded in light and medium winds in order to check the reliability, accuracy and repeatability of the system. Results showed similar trends to the published literature. The accuracy of the system was investigated by wind tunnel tests, with determination of the entire sail shape from the stripe images recorded by the camera-based (VSPARS) system, and was found to be relatively good. Generally the pressure distributions show a leading edge suction peak, occurring at 5 to $10 \%$ of the chord length, followed by a pressure recovery and then a suction increase due to the sail curvature, with finally a reduction in suction near the trailing edge. The drive force coefficient measured on the Stewart 34 is lower than for the J80 because of a non-optimal sail shape due to light winds. On a reaching course, the standard deviation of the pressure signals was largest near the luff, reducing in the stream-wise direction, while it was high on the entire sail section when sailing on a running course.
\end{abstract}

\section{NOMENCLATURE}

$\begin{array}{ll}A & \text { Total sail area }\left(\mathrm{m}^{2}\right) \\ A_{\text {main }} & \text { Main sail area }\left(\mathrm{m}^{2}\right) \\ A_{s p i} & \text { Spinnaker or gennaker area }\left(\mathrm{m}^{2}\right) \\ A W A & \text { Apparent wind angle }\left({ }^{\circ}\right) \\ A W S & \text { Apparent Wind Speed }(\mathrm{m} / \mathrm{s}) \\ C F x & \text { Total Driving Force Coefficient }() \\ C F x_{\text {main }} & \text { Driving Force Coefficient for the main sail only }() \\ C F x_{\text {spi }} & \text { Driving Force Coefficient for the spinnaker only () } \\ C M h & \text { Total Heeling Moment Coefficient ( ) } \\ C M h_{\text {main }} & \text { Heeling Moment Coefficient for the main sail only () } \\ C M h_{\text {spi }} & \text { Heeling Moment Coefficient for the spinnaker only () } \\ C p & \text { Pressure Coefficient }() \\ F E P V & \text { Force Evaluation via Pressures and VSPARS } \\ F x & \text { Total Driving Force (N) } \\ M h & \text { Total Heeling Moment (N.m) } \\ \text { VSPARS } & \text { Visual Sail Position and Rig Shape } \\ T W S & \text { True Wind Speed (m/s) } \\ V S & \text { Boat Speed (m/s) }\end{array}$

$1 \quad$ Introduction

Sail aerodynamics is commonly investigated by using wind tunnel testing (Le Pelley and Richards, 2011; Viola and Flay, 2009) and numerical methods (Richards and Lasher, 2008; Viola, 2009; Lasher and Sonnenmeier, 2008). However, both methods have various drawbacks (Wright et al., 2010). Full-scale testing is usually required to validate results from these methods. Moreover, full-scale testing allows the investigation of yacht performance in real sailing conditions, quantification of the actual forces at work (Le Pelley et al., 2012; Lozej et al., 2012; Augier et al., 2012) and, for example, studies of the effects of the rigging on yacht performance (Augier et al., 2012; Bergsma et al., 2012a, 2012b). Several full-scale sail pressure measurements have been carried out in recent years (Lozej et al., 2012; Viola and Flay, 2010b, 2011; Graves et al., 2008; Puddu et al., 2006). Difficulties in carrying out pressure measurements include the interference of the taps on the sails, the effects of long tubing to connect the taps to the transducers, the recording of an undisturbed static reference 
pressure, and zeroing of the pressure transducers (Puddu et al., 2006; Flay and Millar, 2006), but these difficulties are being overcome with the developing experience of active research groups.

Capturing sail shape at full scale is now commonplace on many racing yachts. Many investigators have developed their own systems for determining sail shape (Lozej et al. 2012, Augier et al., 2012, Le Pelley and Modral, 2008). Various fullscale techniques for the assessment of aerodynamic loads have been developed to date for sailing applications. The use of sail boat dynamometers (Herman, 1988; Masuyama and Fukasawa, 2009; Hochkirch, 2000) has been significant in improving performance prediction. Strain gauging the rigging and sails (Augier et al., 2012) has provided useful information on wind/rig/sail interaction. However, the determination of aerodynamic forces by combining pressure and sail shape measurements at full-scale enables useful insights into steady and unsteady sail aerodynamics to be obtained (Le Pelley et al., 2012; Lozej et al., 2012; Bergsma et al., 2012) by providing considerable detail on how and where the forces are developed.

This paper reports on research on sail aerodynamics which is a continuation of previous work at the University of Auckland and the Naval Academy Research Institute, France, aimed at developing reliable and accurate methods for carrying out full-scale experiments on sailing yachts (Le Pelley et al., 2012; Bergsma et al., 2012a, 2012b). The system developed has been named FEPV (Force Evaluation via Pressures and VSPARS, where VSPARS stands for "Visual Sail Position and Rig Shape"). The recording method combines pressure and sail shape measurements to obtain the aerodynamic forces and moments produced by sails at full scale. Le Pelley et al. (2012) presented the results of the first full-scale test carried out using the FEPV system and a validation of the full system through wind tunnel testing for upwind sailing. Bergsma et al. (2012a, 2012b) describe an application of the FEPV system to upwind sailing, where the effects of shroud tension on upwind sailing performance were investigated.

The present study extends the previous research from upwind to downwind sailing and presents the first published results from simultaneous pressure and shape measurements of downwind sails recorded on the water. The results from pressure and sail shape acquisitions from full scale testing on a Stewart 34 Class yacht in very light winds in New Zealand, and on a J80 Class yacht in stronger winds in France are presented. On the day of the scheduled testing in NZ the wind strength was lower than ideal, but testing could not be changed to another day due to the considerable setup and people commitments. An assessment of the accuracy of the sail shape interpolation procedure was determined by comparing sail shape predictions from VSPARS data with physical measurements in the wind tunnel.

In the present study only the steady approach was used, i.e. time averaged pressures and shapes were investigated. Future work will be dedicated to the dynamic regime.

\section{Components of FEPV system}

\subsection{VSPARS and sail shape measurement}

The VSPARS system was developed in the Yacht Research Unit (YRU) at the University of Auckland by Le Pelley and Modral (2008). It is designed to capture sail shape both in the wind tunnel and whilst sailing. It uses cameras mounted at deck level looking upwards at the sails and rig. The system determines the global locations in Cartesian coordinates of specific targets on the sails and rig. For the rig, these targets comprise coloured dots which are placed at different heights on the mast, typically under the spreaders or at diagonal crosses. On the sails, coloured horizontal stripes are applied to the mainsail, jib and downwind sails. The system is able to dynamically track the stripes, calculate the stripe coordinates in $3 \mathrm{D}$ space and link the stripe positions to the rig deflection.

The main advantage of VSPARS over other systems is that it is able to deal with large perspective effects. Even systems that look up or down at the stripes from the centre of the chord can still have significant perspective effects at the luff and leech ends of the stripes. By accounting for these effects, it is possible to place a camera in the optimum position to see as much of the sail as possible whilst still producing an accurate sail shape, as is done in the VSPARS system. This also enables the system to cope with large changes in sheeting angle. This has been shown to work well even for the highly curved stripes in off-wind sails. An example application of the VSPARS system in the wind tunnel is shown in figure 1. The location of the camera on the model, at the end of the bowsprit in this case, is indicated by the blue arrow.

The main steps of the software can be seen in figure 1. The program essentially takes images using the required camera(s), automatically finds the sail stripes and rig targets, and then combines the results of all the data to give the global $\mathrm{X}, \mathrm{Y}$ and $\mathrm{Z}$ coordinates of the sail stripes and rig relative to the boat origin of the coordinate system.

Further details on the VSPARS performance can be found in Le Pelley and Modral (2008).

The pressure measurement system was custom-built at the Yacht Research Unit at the University of Auckland. The generic layout of the system, as applied to each sail, is shown in figure 2a. Ultra-low range differential pressure sensors (Honeywell XSCL04DC) are the core of the system. The sensors' resolution and range fit the criteria for sailing applications. The pressure sensors are mounted in custom plastic housings, approximately $40 \mathrm{~mm}$ in diameter and $10 \mathrm{~mm}$ thick. On one side, 
they are stuck on the sail with a small hole melted through the sail to a pressure port on the bottom surface of the housing. On the other side, a light sail cloth patch, approximately $150 \mathrm{~mm} \times 150 \mathrm{~mm}$ in area, is applied with another hole through to the opposite pressure port, as shown in figure $2 \mathrm{~b}$. Using this setup, transducers are placed directly at the measuring locations, thus avoiding the issues associated with the use of long tubing and the recording of a reliable static reference pressure (Flay and Millar, 2006).

An operation amplifier (op-amp) is connected directly onto each transducer which amplifies its analogue output (in $\mathrm{mV}$ ) to a signal in the $\pm 2.5 \mathrm{~V}$ range. Using ribbon cable and IDC connectors the transducers are connected to a ribbon cable running along the chord of the sail. Each chord-wise cable terminates on an analogue-to-digital (ADC) converter chip which converts the analogue voltage signal into a 12-bit digital signal. A maximum of 8 taps can be connected to each ADC. For upwind sails this seems to be a sufficient number of taps to catch an accurate chord-wise pressure distribution. For downwind sails it is necessary to increase the number of taps per row because of their more highly varying pressure distributions, and thus two separate systems have been mounted "in parallel" on the sail in the present measurements.

One system can handle 10 of these chips, and therefore 10 sets of 8 transducers. The ADC chips are connected to a continuous ribbon cable along the luff of the sail which terminates at a USB-driven microcontroller box placed at the tack. The microcontroller combines the data from all of the taps on the sail and sends them in a single sentence back to the data acquisition PC. Sampling of a single tap can occur at a frequency up to about $3000 \mathrm{~Hz}$, therefore the system can run over 150 sensors at a sampling rate of $20 \mathrm{~Hz}$, which is higher than required for sailing applications (a frequency of $4-5 \mathrm{~Hz}$ would be enough). If necessary, in order to reduce the effect of any high frequency noise coming from the power supply, the signal can be averaged over a number of readings from each transducer, resulting in a lower effective frequency.

Although the use of a very large number of pressure sensors can lead to a highly accurate interpolated pressure distribution, the FEPV system is intended to be a cost- and time-effective system that could be used by yacht racing syndicates to improve their knowledge of sail design. Therefore a self-imposed limit of 24 sensors for the mainsail and 44 for the gennaker has been used so far, although based on present experience further experiments may be done with a higher chord-wise resolution of pressure taps in order to get an improved description of the pressure distributions, and to reduce the influence of any malfunctioning pressure sensors. Further details on the pressure system can be found in Morris (2011).

\subsection{FEPV data analysis}

The FEPV analysis was coded in Matlab, and uses the output files from VSPARS and the pressure system to obtain the aerodynamic forces and moments. The whole sail surface is created from the recorded stripe shapes and the known tack and head positions from physical measurements a priori. The head is assumed to be flat (with no camber) and to have a small finite length. A spline curve, joining the leech points of the recorded stripes, is extrapolated upwards to the known head height position and also downwards using the known leech length of the sail, to give the head and foot twists respectively, together with the first estimate of the clew position. Unfortunately the foot shape cannot be captured by the camera as it is out of the viewing area with the present VSPARS setup. Therefore an initial foot shape is estimated by fitting a spline curve through the known tack and clew positions together with a $3^{\text {rd }}$ point given by an estimated foot depth and draft position, obtained by extrapolating the depth and draft position of the known stripes. This foot shape is then scaled in both the longitudinal and transverse directions to match the known foot length. Starting from the "low resolution" sail shape defined by the VSPARS stripes and the foot and head positions, a fine quadrilateral mesh is then interpolated over the sail surface.

The sail pressure distributions are obtained from the discrete pressure values recorded by the pressure system which are interpolated using a radial basis interpolation of order 1 (linear). This interpolation scheme is based on the Radial Basis Function, which is a real-valued function whose value depends only on the distance from the reference points, called centres (the pressure taps in this application). Pressure tap positions are defined intrinsically to the sail shape in terms of chord-wise and span-wise percentages. Moreover the use of this interpolation scheme allows a scattered set of pressure measurements to be extrapolated over the sail. The pressures are interpolated to the centre of each geometrical cell in order to obtain a pressure map distribution over the entire surface of both sails, as shown in figure 3. The VSPARS stripes and pressure tap locations are also shown in the figure. Forces in specified directions are computed by integrating the known pressures acting over the cell areas taking into account their surface normal directions. Moment contributions from each cell are calculated about the specified yacht moment reference centre. In the present case the moment reference centre was fixed at an assumed buoyancy centre.

\section{FEPV system validation}

In an earlier study (Le Pelley et al., 2012) the FEPV system was validated for upwind sailing through wind tunnel testing. Results from the FEPV system were compared in terms of forces and moments to measurements from the wind tunnel force balance, and good agreement was found. The tests for the upwind validation were conducted at an apparent wind angle 
(AWA) of $25^{\circ}$ and a heel angle of $20^{\circ}$. Three types of trim change were investigated. Firstly, the main was swept through 8 trim settings from hard sheeted to fully eased using a combination of both mainsheet and traveller, whilst the jib was left in a standard trim position. Secondly, the jib was swept from hard sheeted to fully eased using the jib sheet, whilst the main remained at a standard trim. Finally, both sails were eased together over 8 settings. The trends shown by the FEPV calculations compared well with the force balance results. The driving force and rolling moment from the sails predicted by the FEPV method were 10\% more and 5\% less respectively than measured by the force balance. These differences are thought to be due to the additional windage from the mast, rigging etc., which is not measured by the sail pressure integrations, which would cause the force balance to give a lower driving force and a higher heeling moment for the upwind AWA of $25^{\circ}$ which was used for the validation tests. A more detailed description of the validation results can be found in (Le Pelley et al., 2012).

A complete validation of the FEPV system in terms of aerodynamic forces for downwind sailing needs much more effort and has not been carried out to date, but is planned in future work. As a first step, the determination of downwind sail shape has been validated in the wind tunnel as described below. Pressure measurements on downwind sails have been carried out both in the wind tunnel and at full scale (e.g. Viola and Flay, 2009, Le Pelley et al., 2012, Bot et al., 2013) and the measurement system used in this work is judged to be reliable. The VSPARS system itself had been previously validated both for upwind and downwind sails (Le Pelley and Modral, 2008). Indeed, particular attention was needed to assess the accuracy of the foot shape and the determination of the clew position, as these positions are obtained from extrapolations rather than from direct VSPARS measurements. Wind tunnel tests were carried out on a model scale VO70 yacht, shown in figure 4, to obtain data for this assessment. Two different gennakers were tested at AWAs varying from $60^{\circ}$ to $120^{\circ}$ in order to cover the full range of AWAs of interest at full scale.

The clew, foot depth, and draft positions were measured physically during each test, and the sail stripe positions were also recorded by VSPARS, and used by the FEPV software to determine the sail shape. The results of this comparison are shown in Table 1. For these shape validation measurements and computations, the moment reference centre is located at the base of the mast, with $x$ positive forward, $y$ positive towards port and $z$ positive upwards. Differences in clew positions in the $x, y$ and $z$ directions are given in Table 1. Foot depth and draft position are expressed as a percentage of the chord length. Average chord lengths of $1400 \mathrm{~mm}$ and $1100 \mathrm{~mm}$ for sails 1 and 2 respectively can be used for reference.

The results show that the FEPV system can predict the clew position with an accuracy of up to $\pm 70 \mathrm{~mm}$ (but usually much less). Fairly good agreement in foot shape is obtained as well, with errors within 5\% of the chord length. As a general pattern, the present FEPV analysis software overestimates the foot depth and underestimates the draft position. It was observed during these FEPV validation tests that the foot of the sail was constantly moving, probably due to shedding of the foot vortex, which is a common characteristic of downwind sailing. Therefore the physical location of the sail could not be determined to better than a few tens of $\mathrm{mm}(30-50 \mathrm{~mm})$ during the tests, and so a distance of about $40 \mathrm{~mm}$ is representative of the validation accuracy.

Table 1: Comparison of clew coordinates and foot shape between FEPV and physical measurements.

\begin{tabular}{|c|c|c|c|c|}
\hline & \multicolumn{2}{|c|}{ Sail 1} & \multicolumn{2}{|c|}{ Sail 2} \\
\hline & 60 AWA & $80 \mathrm{AWA}$ & $100 \mathrm{AWA}$ & $120 \mathrm{AWA}$ \\
\hline Coordinate & \multicolumn{4}{|c|}{ difference $[\mathrm{mm}]$ between FEPV and Exp measure } \\
\hline X_clew & 27 & 41 & -10 & -3 \\
\hline y_clew & 4 & -63 & -27 & -34 \\
\hline Z_clew & 50 & 16 & -36 & -46 \\
\hline \multicolumn{5}{|c|}{ Sail 1} \\
\hline & \multicolumn{2}{|c|}{60 AWA } & \multicolumn{2}{|c|}{80 AWA } \\
\hline$[\%$ chord $]$ & Experimental & FEPV & Experimental & FEPV \\
\hline foot depth & 16.7 & 18.1 & 25 & 23 \\
\hline foot draft & 34.1 & 39.4 & 39 & 41.2 \\
\hline \multicolumn{5}{|c|}{ Sail 2} \\
\hline & \multicolumn{2}{|c|}{100 AWA } & \multicolumn{2}{|c|}{120 AWA } \\
\hline$[\%$ chord $]$ & Experimental & FEPV & Experimental & FEPV \\
\hline foot depth & 30.9 & 27.8 & 36.6 & 30 \\
\hline foot draft & 44.9 & 50.5 & 44.7 & 50.7 \\
\hline
\end{tabular}




\subsubsection{Stewart 34 and J80 characteristics}

As mentioned in section 1, in this work two different tests are presented in order to show the feasibility of the FEPV system as a measuring technique at full scale. Table 2 lists the main features of the downwind sails used on the Stewart 34 and J80 yachts respectively, together with a summary of the test conditions for the tests.

Table 2:Stewart 34 and J80 downwind sails characteristics.

\begin{tabular}{|c|c|c|c|}
\hline & Stewart 34 & J 80 & \\
\hline Spinnaker area & 32 & 63 & $\mathrm{~m}^{2}$ \\
\hline Luff length & 8550 & 12000 & $\mathrm{~mm}$ \\
\hline Leech length & 7960 & 9550 & $\mathrm{~mm}$ \\
\hline Mast height & 12600 & 11450 & \\
\hline Sail features & $\begin{array}{c}\text { Flat luff } \\
\text { Flatter spinnaker } \\
\text { Spinnaker size small } \\
\text { compared to yacht size }\end{array}$ & $\begin{array}{c}\text { Rounded luff } \\
\text { Fuller spinnaker }\end{array}$ & $\mathrm{mm}$ \\
\hline VSPARS stripe 3/4 length & 3453 & 5860 & $\mathrm{~mm}$ \\
\hline VSPARS stripe 1/2 length & 5208 & 7720 & $\mathrm{~m} / \mathrm{s}$ \\
\hline VSPARS stripe 1/4 length & 5327 & 6.7 & $\mathrm{~m} / \mathrm{s}$ \\
\hline Average TWS & 3.6 & 3.6 & \\
\hline Average Boat Speed & 1.3 & $4.7 \mathrm{~m} / \mathrm{s} \mathrm{at}$ & \\
\hline Max Boat Speed & $72^{\circ}$ AWA, $4.4 \mathrm{~m} / \mathrm{s} \mathrm{AWS}$ & $91^{\circ}$ AWA, $7.3 \mathrm{~m} / \mathrm{s} \mathrm{AWS}$ & \\
\hline
\end{tabular}

Figures 5a and 5b show images of the S34 gennaker and J80 spinnaker respectively, as recorded by the VSPARS cameras when sailing at an AWA of about $90^{\circ}$.

\subsubsection{Stewart 34 test setup}

A Stewart 34 class yacht was used for the full-scale testing in NZ. It was decided to equip the yacht with an available gennaker, which was a 1/3rd-scale AC33 gennaker sized to fit a smaller boat, namely an International Platu25, which is about $7.5 \mathrm{~m}$ long. The gennaker was hoisted from a pole held against the forestay. Although this setup was not ideal, the gennaker flew in a reasonable manner, as can be seen in figure $5 \mathrm{a}$.

Both the mainsail and gennaker were equipped with VSPARS stripes and differential pressure transducers. A GPS unit, sampling at a rate of $2.5 \mathrm{~Hz}$, was used to record the speed over ground and boat location, while the boat instruments logged boat speed through the water at $1 \mathrm{~Hz}$, and wind speed and direction at $0.2 \mathrm{~Hz}$. An Inertial Measurement Unit (IMU) was placed in the yacht cabin and logged the boat motion at $10 \mathrm{~Hz}$. The VSPARS stripe recording system uses a sampling frequency of about $0.3 \mathrm{~Hz}$ which enabled several images to be averaged to obtain the shapes of the stripes for the FEPV calculations. The sampling frequency for the pressures was $60 \mathrm{~Hz}$, but these were averaged over 30 measurements to filter out higher frequency fluctuations and resulted in an effective sampling rate of $2 \mathrm{~Hz}$. A custom-made data acquisition unit recorded all these data, each one at its own sampling rate, and so the data were all time stamped to enable subsequent synchronous processing of the data streams.

For the Stewart 34 tests, the mainsail was equipped with three rows of 8 sensors placed at $1 / 4,1 / 2$ and $3 / 4$ sail heights, while the gennaker was equipped with three stripes of 12 sensors at $1 / 4,1 / 2$ and $3 / 4$ sail heights plus a $4^{\text {th }}$ stripe of 8 sensors placed at $7 / 8$ of the height. The additional stripe at $7 / 8$ height was used because previous studies in the wind tunnel have shown that the chord-wise pressure distribution on a gennaker can change dramatically between $3 / 4$ and $7 / 8$ heights. Therefore it was felt that a simple interpolation up to the head using the $3 / 4$ stripe data would not be sufficiently accurate. The pressure sensors on the mainsail were covered with sail-cloth patches, while the sensors on the gennaker were placed into pockets created by the overlap of adjacent sail panels.

The measurements were performed in the Hauraki Gulf, Auckland, NZ, in a fairly constant but very light breeze of between 6 and 8 knots, in an area with insignificant tidal flow with almost flat water. In this light breeze the sails were just able to fly. Such low wind speeds, which varied from 0 to $30 \mathrm{~Pa}$ for the gennaker and from 0 to $15 \mathrm{~Pa}$ for the mainsail, made it difficult to accurately measure the pressures across the sails due to the sensitivity of the pressure transducers. More wind 
would have been preferred, but the tests were planned for a certain day and could not be rescheduled, and the wind was light on the day. Nevertheless, the FEPV system proved to be effective and provided repeatable results, as discussed in section 4.2 .2

The aim of the tests was to check the reliability and accuracy of the FEPV system, the repeatability of the test results, and to qualitatively study the flow around the sails by analysing the pressure distributions and the sail shape. The yacht was sailed at its optimum trim on starboard tack for AWAs varying from $65^{\circ}$ to $115^{\circ}$. A total of 24 runs were carried out, each about $60 \mathrm{~s}$ long. Sail trim (optimal sail trim with gennaker on the verge of luffing) was kept constant for each run and the boat heading was kept as straight as possible to enable the results to be averaged over the run time (45 - $60 \mathrm{~s})$. Measurements from the instruments on board (including the pressures and sail shapes) were averaged over the run-time, and the FEPV code used the average values for the computations. The VSPARS software allows an average sail shape to be obtained from a given set of images by simply averaging the positions of each recorded point on the sail stripes.

In this study only the steady approach is considered, as explained above. Future work will be dedicated to the investigation of the dynamics involved in sailing (oscillations, waves propagating on the sail, correlation between timedependent shape and pressures, etc.)

\subsubsection{Stewart 34 Results}

In 2009 (Viola and Flay, 2009) carried out wind tunnel tests on asymmetric spinnakers. Their results show that on the leeward side of the spinnaker the pressure, in separated flow, has a negative peak at the leading edge, followed by a slow pressure recovery up to the trailing edge. In attached flow the suction peak at the leading edge is followed by a quick pressure recovery at around $10 \%$ of the curve length followed by a second suction peak due to the section curvature. Downstream of the second suction peak, which occurs between $10 \%$ and $40 \%$ of the curve length, the pressure becomes less negative, and then constant due to the trailing edge separation.

Figures 6 and 7 show typical full-scale pressure coefficient distributions for the gennaker and mainsail respectively at different AWAs plotted against the sail curve length percentage. In all the figures showing pressure and force coefficients, the dynamic pressure was calculated from the apparent wind speed (AWS), and the pressure differences are leeward minus windward, thus giving negative values. The pressure coefficient plots have the negative direction upwards, as is common in presenting pressure distributions on wings. The suctions are generally higher over the entire surface for lower AWAs. This trend is confirmed in terms of driving force determined by integration, which is higher for the lower AWAs. The flow around the top stripe of the gennaker is stalled for all AWAs, as can be seen from the lack of a pressure recovery after the leading edge peak, which occurs at around $5 \%$ of the curve length. The rows at $3 / 4$ and $1 / 2$ of the height show similar behaviour; the leading edge suction peak, occurring at 5 to $10 \%$ of the chord length is followed by a pressure recovery (perhaps due to an intermittent leading edge separation-bubble reattachment), a suction increase due to the sail curvature, and then a reduction in suction as the trailing edge is approached. However the sail is not able to generate much suction, probably due to the very light winds, and therefore the suction due to curvature is very small. This can be confirmed by the small values of the pressure differences, which range between 10 and $30 \mathrm{~Pa}$. The bottom row at $1 / 4$ height has similar chord-wise distributions, with even smaller suctions generated by the sail curvature, and only for the lowest AWAs. There is something unexplained happening at $25 \%$ of the chord for AWA $=89^{\circ}$, where the suctions are lowest, perhaps due to a problem with the pressure tap, or a crease in the sail. Increased AWAs over $100^{\circ}$ drastically flatten the pressure distributions in the proximity of the leading edge.

It is worth commenting on the consistency of the pressure distributions obtained in such light airs. When testing at fullscale, zeroing of the pressure sensors is not an easy task because the wind cannot be turned off and because of the sensitivity of the transducers to their orientation. In practice, zeroing was carried out with the gennaker inside a bag to obtain a uniform pressure and was repeated after turning the bag over so that it was upside down, and thus all transducers were rotated through $180^{\circ}$ about a horizontal axis. This was done because the sensors' zeroes are sensitive to their orientation.

The pressure differences on the mainsail shown in figure 7 are even lower than on the gennaker, having maximum values of only $15 \mathrm{~Pa}$. For the distributions at an AWA of $72^{\circ}$ an error bar has been added which shows plus or minus one standard deviation of the pressure coefficient for the runs analysed. The standard deviation is usually higher for the pressure taps in close proximity of the leading edge, and lower when approaching the trailing edge. Moreover, higher values of the standard deviation are achieved in the higher pressure rows, particularly on the $7 / 8$ stripe, for which the flow is stalled, as shown in figure 8 for an AWA of $89^{\circ}$. The standard deviation is a useful tool to help understand if the flow is attached or not. A high standard deviation is indicative of separated flow because of its very unsteady behaviour as eddies form, grow and then are shed from the sail causing large changes in local surface pressures.

The flow on mainsails is affected by the presence of the mast (Viola and Flay, 2010a) which usually produces a separation bubble behind it with a low recirculation flow velocity and a low pressure core on the leeward side of the front part of the mainsail. This helps to explain the suction peak at 7 to $15 \%$ of the chord exhibited in figure 7 , followed by pressure recovery where the flow reattaches. Figure 7 shows two further suction peaks at all heights and for all AWAs. The 
reasons for these are not clear, but might be due to the sail curvature not being very fair due to the lack of pressure difference across it, thus resulting in a wavy sail surface.

Another atypical behaviour is the presence of positive values of differential pressures before and after the leading edge suction peak. Again, this might be due to some reverse flow in the separated area. This behaviour is not likely to be caused by incorrect zeroing of the pressure transducers, as they were zeroed several times on shore (before and after the tests) and at sea during the measurements. Taking into account the drift of the sensors with time and temperature, their sensitivity to their orientation, and the noise during the measurements, the estimated accuracy of the pressure measurements for the Stewart 34 tests is about $\pm 2.5 \mathrm{~Pa}$, and thus \pm 0.3 in terms of pressure coefficients for the actual wind conditions. Hence this atypical behaviour may be the result of experimental error.

It is worth noting that the pressure coefficient distributions show very similar shapes for a wide range of AWAs, in spite of the large values of the standard deviation especially in the close proximity of the leading edge. This can be explained by analysing the shape of the sail sections as outputted by VSPARS and shown in figure 9 . Note that the bow of the yacht is orientated in the $+x$ direction. Only the section at $1 / 2$ of the height is presented as indicative. As the AWA is increased, the luff moves more to windward, towards and across the centreline of the boat and the leach moves aft and outboard, thus opening the sail up. However, the section shape does not change significantly in spite of the large $40^{\circ}$ change in AWA shown. This might be due to the light winds encountered during the tests, and therefore the small loads acting on the gennaker. This behaviour might also be due to the sub-optimal hoisting method used for the gennaker with the tack attached to a pole on the forestay, but this could not be established with certainty.

The tests showed very good repeatability in terms of pressure, as discussed herewith, and in terms of forces, as discussed later in this section. Figure 10 shows pressure coefficients for several runs performed at similar AWAs at about $85^{\circ}$. Only the pressures at row $1 / 2$ are shown, but similar behaviour was found at all heights.

To analyse aerodynamic forces, total and single sail drive force coefficients are computed as follows.

$$
\begin{aligned}
& \mathrm{CFX}_{\text {main }}=\mathrm{Fx}_{\text {main }} /\left(0.5 * \rho * \mathrm{~A}_{\text {main }} * \mathrm{AWS}^{2}\right) \\
& \mathrm{CFX}_{\mathrm{spi}}=\mathrm{FX}_{\mathrm{spi}} /\left(0.5 * \rho * \mathrm{~A}_{\mathrm{spi}} * \mathrm{AWS}^{2}\right) \\
& \mathrm{CFX}=\left(\mathrm{CFX}_{\mathrm{spi}} * \mathrm{~A}_{\mathrm{spi}}+\mathrm{CFX} \mathrm{X}_{\text {main }} * \mathrm{~A}_{\text {main }}\right) /\left(\mathrm{A}_{\text {main }}+\mathrm{A}_{\mathrm{spi}}\right)
\end{aligned}
$$

Heeling moment coefficients are defined similarly, except that the sail area is at the power $3 / 2$ in the normalisation.

The variations of the total drive force (CFx) and heeling moment coefficients (CMh) with AWA are shown in figure 11. The values obtained are quite small for CFx and high for CMh, in the authors' experience, for the whole range of AWAs investigated. This is thought to be due to the light winds experienced during this test, as supported by figure 12 where CFx is shown to increase with increasing TWS in the investigated range ( 3 to $5 \mathrm{~m} / \mathrm{s}$ ), for similar apparent wind angles (see also Section 4.4.1). Hence it appears that the sails become more efficient as the TWS increases.

For all AWAs the mainsail contributes only a very small amount to the overall drive force compared to the gennaker. Indeed, $\mathrm{CFx}_{\text {spi }}$ varies between 0.45 and 0.85 for the gennaker and $\mathrm{CFx}_{\text {main }}$ is only up to 0.11 for the mainsail, as shown in figure 13. This is as-expected, but note that the presence of the mainsail increases the loading on the gennaker due to the upwash it generates upwind of the sail. Similarly, the gennaker contributes mostly to the heeling moment, as shown in figure 13 . $\mathrm{CFx}_{\text {spi,main }}$ for each sail is normalised by each single sail area (gennaker or mainsail respectively), while $\mathrm{CMh}_{\text {spi,main }}$ is normalised by the area of each single sail to the power $3 / 2$.

The heeling moment coefficients from the more highly loaded gennaker generally decrease with increase in the AWA, as shown in figure 13. The scatter in the mainsail and gennaker results might be due to the different behaviour of the boat at lower and higher wind speeds. The values of heel angle are generally low (figure 14) and increase in an approximately linear manner with increase in the heeling moment (and thus decrease with increase in AWA).

Figures 15a and 15b show the overall drive force (Fx) and boat speed (Vs) plotted against the AWA. In this case a clear trend of increasing Fx for decreasing AWA can be identified, as well as the expected increase in Fx for the runs performed in slightly stronger winds (square symbols in figure 15). The boat speed is generally higher for low AWAs (giving a higher AWS), and this is associated with a small increment in heel angle. This is as-expected since the lower AWAs give the higher thrust.

In this section discussing the results from the full-scale measurements on the Stewart 34 class yacht, the measurements were averaged over each run, under the assumption that the conditions and yacht/sail responses were steady. To clarify this assumption, an extract from the raw measurements is shown in figure 16. Time histories of AWA, boat speed, heel angle and pitch angle are shown. Each sample is shown at its own sampling rate. For the present tests, boat speed and AWA were logged with the boat instruments, and therefore they were measured at a very low sampling rate compared to the other measurements. Regarding the steadiness, the authors were particularly focused on the AWAs. As a rule of thumb, a variation not greater than $5-6^{\circ}$ in the AWA was considered to be small enough to assume a steady run. 


\subsubsection{J80 test setup}

As stated above, an Ecole Navale J80 yacht was used to undertake pressure measurements on sails in stronger winds, in the Brest Gulf, France. This yacht flies an asymmetric spinnaker (figure 5b) of area $63 \mathrm{~m}^{2}$. Both the mainsail and spinnaker were equipped with VSPARS, although only the spinnaker was instrumented with differential pressure transducers, as shown in figure 17.

In a similar manner to what was done for the Stewart 34, the J80 spinnaker was equipped with four rows of pressure taps at approximately $1 / 4,1 / 2,3 / 4$ and $7 / 8$ of the sail height. Sensors were placed on the sail along lines that joined the $1 / 4,1 / 2,3 / 4$ and $7 / 8$ height positions on the luff and leach, as the luff was much longer than the leech on the J80 spinnaker. Hence the lines of the pressure taps were not parallel to each other. Sensors were placed on the port side of the spinnaker and covered with sail-cloth patches to reduce their interference with the flow. Unfortunately the analogue to digital converter connected to first 8 taps of the $1 / 4$ height row unplugged during the tests because of the excessive stretching of the spinnaker cloth due to the sail motions. Therefore, pressure data for this row are only available for those few runs performed before this failure occurred.

An Inertial Measurement Unit (Xsens MTi-G) was placed at the rotation centre of the hull (for small angles of heel) and was used to record boat motions. An ultrasonic 3D anemometer was fixed to the mast top and a boat speed indicator was installed onto the J80 hull. A fluxgate compass and a GPS were deployed inside the boat. All sensors on board were linked to an inboard computer. Acquisition was controlled by RTmaps, a dedicated piece of software for synchronisation and date stamping developed by Intempora. RTmaps is well suited for real-time data acquisition, as sensors were free to communicate with the computer at their own frequency and each sample was stored in the buffer at its own sampling rate. Re-sampling was applied before off-line analysis to obtain synchronous data.

The measurements were performed in the Brest Gulf, France, with a sea breeze varying between 10 and 15 knots and almost flat water. The yacht was sailed at its optimum trim (it was a dynamic trim, trying to keep the spinnaker always on the verge of luffing, and boat heading was kept as straight as possible in order to keep a constant AWA) on a wide range of AWAs varying from $58^{\circ}$ to $143^{\circ}$, both on port and starboard tacks. Starting with the time series, all measurements were averaged over chosen run-times characterised by relatively small changes in AWA. This was intended to give representative mean values of pressures for particular apparent wind speed and direction characteristics.

\subsubsection{J80 test results}

In this section pressure coefficients are plotted against the sail curve percentage at different AWAs. The pressure coefficients are calculated as average pressure differences (leeward minus windward) divided by the dynamic pressure formed from the average apparent wind speed (AWS) over the run in a similar manner as used for the Stewart 34 analysis. Figure 18 is an extract of the results showing the pressure coefficient distributions for a wide range of AWAs. It can be seen that the highest suctions are achieved at AWAs of about $80^{\circ}-90^{\circ}$, particularly for the higher stripes.

A few interesting observations are evident by comparing pressure coefficient distributions for runs with similar AWAs, as in figure 19 which shows Cps for runs with the AWA close to $85^{\circ}$ on starboard tack. The Cp distributions are very similar among the three different runs, but two different situations can occur in the proximity of the leading edge, either a high $\mathrm{Cp}$ or a low $\mathrm{Cp}$ (visible at $1 / 2$ and $1 / 4$ of the sail height). It is believed that this difference in pressure distributions is due to different trims of the spinnaker during the runs, and suggests the idea that pressures close to the leading edge are very sensitive to small changes in trim and to small variations in instantaneous AWA. This is in accordance with the way that sailors fly a spinnaker at its optimum point of sailing, i.e. on the verge of luffing. This difference in pressure distributions is usually observed at $1 / 4$ and $1 / 2$ of sail height, and may sometimes be observed on the higher level stripes. Note also the error bars corresponding to \pm 1 standard deviations in figure 1 for only one of the runs for clarity. It is evident that the standard deviation is usually much higher in the close proximity of the leading edge (up to $20 \%$ of the curve) because of the sail being on the verge of luffing, and sometimes flapping, while it is quite small towards the trailing edge.

Figure 20 shows the standard deviation of the $\mathrm{Cps}$ for several runs from $78^{\circ}$ to $138^{\circ}$. While the observation mentioned above still stands for the tightest AWAs $\left(80^{\circ}-90^{\circ}\right)$ with a standard deviation of about $0.2-0.3$ on most of the sail section, but reaching 0.8 near the luff, the behaviour is different for deep AWAs $\left(115^{\circ}-140^{\circ}\right)$. In the latter case, the standard deviations are high (1.5 to 2.5$)$ on the whole sail section, corresponding to a variation amplitude of the same order of magnitude, if not larger, than the $\mathrm{Cp}$ mean value. This is thought to be related to a more unsteady flow because of massive separation over the high camber high incidence sections. Moreover, the sail shape is expected to be less stiff and more unstable for deep AWAs as it is less stretched and more curved. This would result in higher lateral displacements and then higher pressure oscillations over the entire sail, not only around the luff.

To support the results shown in figure 20, samples of several pressure time histories are shown in figure 21 , namely time histories of 100 seconds duration from the second tap on the $1 / 2$ height stripe at $10 \%$ of the curve length for two ranges of AWA: running and reaching. It can be seen that pressure variations are much larger for the deep running AWAs, while the pressures vary significantly less when the AWAs are less than $100^{\circ}$ for the reaching runs. Note that pressure data presented 
in figure 21 are not raw data, but are smoothed and re-sampled at $100 \mathrm{~Hz}$ to facilitate the plotting. The raw data exhibited the same features, so the oversampling did not affect the conclusions that can be drawn from the time histories.

The comparison between the pressure distributions at similar AWAs but for runs sailed on different tacks in figure 22 gives an idea of the relatively good repeatability of the tests and of the relatively small influence of the pressure sensors on the flow. The pressure sensors were taped onto one side of the sail and covered with sail-cloth patches, as discussed in section 2.2. It was expected that these patches would have some effect on the flow over the sail and therefore the resulting pressures, especially when they are on the leeward side of the sail. Figure 22 shows the $\mathrm{Cp}$ distributions for two runs sailed at an AWA of about $77^{\circ}$ on starboard and port tacks respectively. Note that the pressure sensors are placed on the port side of the spinnaker, and therefore they are on the windward side of the sail when sailing on port tack, while they are on the leeward side when sailing on starboard tack. The distributions are very similar in shape and the observed differences are well lower than the standard deviations. It is reassuring that these results confirm that the presence of the pressure sensors does not significantly affect the flow over the sail, as also observed by Herman (1988).

The variation of the drive force $\left(\mathrm{CFx}_{\mathrm{spp}}\right)$ and heeling moment coefficients $\left(\mathrm{CMh}_{\mathrm{spi}}\right)$ with $\mathrm{AWA}$ as obtained through FEPV are shown in figure 23 for both the S34 and J80. As mentioned above, one of the ADCs unplugged during the tests, so pressures at $1 / 4$ of the height are available only for a limited number of runs. Therefore, the results presented herewith refer only to those runs in which all the pressures were measured. Only pressures on the spinnaker were recorded during the test, thus the forces and moments are those produced by the spinnaker alone. The values of $\mathrm{CFx}_{\mathrm{spi}}$ are of the order of $0.8-1$ for AWAs between $80^{\circ}$ and $100^{\circ}$, with the greatest $\mathrm{CFx}_{\mathrm{spi}}$ achieved at an AWA of about $90^{\circ}$. The $\mathrm{CMh}_{\text {spi }}$ decreases with AWA as expected, and reaches its maximum value of about 1.63 at an AWA of $67^{\circ}$.

\subsubsection{Comparison between $J 80$ and $S 34$ test results}

The aim of this work is to demonstrate the feasibility of on-water force measurements by measuring pressures and sail shapes (the FEPV method) rather than to give a deep insight into sail aerodynamics. However, it is possible to compare the results obtained on the two downwind tests performed with the J80 and S34 yachts and make some comments.

Figure 24 shows a comparison of pressure coefficients obtained from the S34 and J80 yachts. The Cp trends are discussed separately in sections 4.2.2 and 4.3.2. In this section the results from an apparent wind angle of $85^{\circ}$ are compared. Although there are some differences due to the different sail shape/size and different wind/sea conditions, the $\mathrm{Cp}$ distributions have similar features and the same order of magnitude. At the higher levels ( $3 / 4$ and $7 / 8$ of the sail height) the Cps for the J80 are usually higher. Several Cp distributions (at similar AWAs) are plotted from the S34 tests to give an idea of the variability of the measured pressures.

Figure 23 shows a comparison of drive force and heeling moment coefficients from both tests. The forces produced by the spinnaker-only are shown in this comparison (the J80 mainsail was not equipped with pressure sensors). There is a noticeable difference in the value of the coefficients. Indeed, values of $\mathrm{CFx}_{\mathrm{spi}}$ are significantly higher on the J80 compared to the $\mathrm{S} 34$, while $\mathrm{CMh}_{\text {spi }}$ produced by the $\mathrm{S} 34$ gennaker are higher compared to the $\mathrm{J} 80$, especially at low AWAs. Overall, the aerodynamic force coefficients (force magnitude normalised by the dynamic pressure and sail area)) are the same order of magnitude, and the $\mathrm{Cp}$ distributions are similar on both tests. Hence, the source of this difference in $\mathrm{CFx}_{\mathrm{spi}}$ and $\mathrm{CMh}_{\mathrm{spi}}$ is expected to come from the shape and orientation of the sails. Figure 25 shows the shape of the sails at sections $1 / 2$ as determined from VSPARS for the J80 and S34, at AWAs of $91^{\circ}$ and $89^{\circ}$ respectively. The sections are plotted in the horizontal plane, in real coordinates from the mast base with $+x$ in the direction of the bow. Figure 25 shows that the J80 shape "opens up" more (leech more outboard) compared to the S34 shape, which is instead much more "closed", i.e. with a lower angle between the section chord and yacht centreline. Similar behaviour is found at all heights. This may be due to the light winds in the S34 tests, and is very likely to be the source of the higher $\mathrm{CMh} / \mathrm{CFx}$ ratio for the $\mathrm{S} 34$, since the pressure difference across the sail will result in a larger force in the +y (heeling) direction, than for the J80.

\section{Conclusions}

An innovative method, which combines simultaneous on-water pressure and sail shape measurements, for determining the aerodynamic forces and moments produced by highly curved downwind yacht sails at full scale is investigated in this research. The results show that the method works well. The sail shape measurement component of the system has been investigated for highly curved asymmetric spinnakers through wind tunnel testing, and has been shown to predict accurate sail shapes. The system has been used for downwind sailing at full scale in low and moderate wind conditions and with different sails. It was found that more reliable results were obtained in higher wind speeds because the sensors were able to record higher pressure differences, and the sails developed fairer shapes. However, it worked well and provided repeatable pressure distributions even in the lower wind speeds used for the Stewart 34 testing. The comparison of runs performed at 
similar AWAs on opposite tacks showed that the presence of the pressure sensors did not significantly affect the flow over the sails, as the pressure distributions were very similar on opposite tacks.

In the present study only the steady approach was considered, i.e. measurements from the instruments on board (including the pressures and sail shapes) were averaged over chosen run-times characterised by relatively small changes in AWA. This was intended to give representative mean values of pressures for particular apparent wind speed and direction characteristics. However, the observed fluctuations and the high values of standard deviation measured for the pressures (especially near the luff) suggest that an unsteady approach is necessary for a better understanding of downwind sails, and further investigation of the dynamic behaviour of the sail shape, pressures and forces is underway. Nevertheless, the method is shown to be relevant for evaluating time-averaged forces and some important conclusions can be drawn.

It was shown that drive force coefficients determined using the FEPV system give much higher values for the gennaker than for the mainsail in full-scale, thus confirming similar results measured in the wind tunnel. In the Stewart 34 tests the drive force coefficients were shown to increase with TWS over the range of true wind speeds from 3 to $5 \mathrm{~m} / \mathrm{s}$, suggesting higher efficiency of the sails in stronger winds. The pressure distributions showed similar characteristics to other published results obtained from wind-tunnel experiments and numerical computations. Except when the flow over a sail section is clearly stalled, generally the pressure distributions showed a leading edge suction peak followed by a pressure recovery and then a suction increase due to the sail curvature, with finally a reduction in suction as the trailing edge is approached.

In the sets of measurements discussed in the paper, the flow around the $7 / 8$ stripe of the spinnaker is stalled for all AWAs, both in light and moderate winds. This stalled flow behaviour is confirmed by the standard deviations of the pressure signals which were higher for the $7 / 8$ stripe than for attached flows at lower heights.

Pressures close to the leading edge were shown to be very sensitive to small changes in trim and to small variations in instantaneous AWA, with high suctions when it was near to luffing, and this observation agrees with the way that sailors trim a spinnaker to have it on the verge of luffing for optimum performance. For the tightest AWAs on a reaching course, when the flow is mostly attached over the sail section, the standard deviation of the pressure signals is largest near the luff, reducing in the stream-wise direction. For the deepest AWAs on a running course, the standard deviation of the pressures is high over the whole sail section, probably due to a more detached flow and an unstable sail shape. In a dynamic investigation, it would be interesting to analyse the pressures and shape oscillations and their phase to look for possible pumping or propagating pressure waves in the sail structure.

The next step in this project is to use the FEPV system to investigate unsteady sail aerodynamics at full scale for both upwind and downwind sailing.

\section{Acknowledgements}

This project has received funding from the European Union's Seventh Programme for research, technological development and demonstration under grant agreement No PIRSES-GA-2012-318924, and from the Royal Society of New Zealand for the UK-France-NZ collaboration project SAILING FLUIDS.

\section{References}

Augier, B., Bot, P., Hauville, F., Durand, M., 2012. Experimental validation of unsteady models for fluid structure interaction: Application to yacht sails and rigs. Journal of Wind Engineering and Industrial Aerodynamics 101(0): 53-66.

Bergsma, F., Motta, D., Le Pelley, D.J., Richards, P.J., Flay, R.G.J., 2012a. Investigation of sailing yacht aerodynamics using real time pressure and sail shape measurements at full scale, $18^{\text {th }}$ Australasian Fluid Mechanics Conference, Launceston, Australia.

Bergsma, F., Motta, D., Le Pelley, D.J., Richards, P.J., Flay, R.G.J., 2012b. Investigation of shroud tension on sailing yacht aerodynamics using full-scale real-time pressure and sail shape measurements, $22^{\text {nd }}$ International HISWA Symposium on Yacht Design and Yacht Construction, Amsterdam.

Bot, P., Viola, I.M., Flay, R.G.J., Brett, J.S., 2013, Wind-Tunnel Pressure measurements on Rigid Model-Scale Downwind Sails, 3rd International Conference on Innovation for High Performance Sailing Yachts INNOV'SAIL, Lorient, France, pp. 119-127

Flay, R.G.J., Millar, S. 2006. Experimental Considerations Concerning Pressure Measurements on Sails: Wind Tunnel and Full-Scale, 2nd High Performance Yacht Design Conference, Auckland, New Zealand. 
Graves, W., Barbera, T., Braun, J.B., Imas, L., 2008.Measurement and Simulation of Pressure Distribution on Full Size Sails, 3rd High Performance Yacht Design Conference. Auckland, New Zealand.

Herman, J.S., 1988. A Sail Force Dynamometer: Design, Implementation and Data Handling, Massachusetts Institute of technology, Cambridge.

Hochkirch, K., 2000. Design and Construction of a Full-Scale Measurement System for the Analysis of Sailing Performance, Technical University of Berlin.

Lasher, W.C., Sonnenmeier, J.R., 2008.An Analysis of Practical RANS simulations for spinnaker aerodynamics, Journal of Wind Engineering and industrial Aerodynamics, 96, 143-165.

Le Pelley, D.J., Modral, O., 2008. VSPARS: A combined sail and rig shape recognition system using imaging techniques,3rd High performance Yacht Design Conference, Auckland, New Zealand.

Le Pelley, D.J., Richards, P.J., 2011. Effective Wind Tunnel Testing of Yacht Sails Using a Real-Time Velocity Prediction Program, $20^{\text {th }}$ Chesapeake Sailing Yacht Symposium, SNAME, Annapolis.

Le Pelley, D.J., Morris, D., Richards, P.J., 2012. Aerodynamic force deduction on yacht sails using pressure and shape measurement in real time, 4th High Performance Yacht Design Conference: Auckland, New Zealand.

Lozej, M., Golob, D., Vrtic, B., Bokal, D., 2012. Pressure Distribution on Sail Surfaces In Real Sailing Conditions. 4th High Performance Yacht Design Conference, .Auckland, New Zealand.

Masuyama, Y., Fukasawa,T., 2009.Database of sail shapes versus sail performance and validation of numerical calculations for the upwind condition, Journal of Marine technologies.

Morris, D., 2011. Derivation of Forces on a Sail using Pressure and Shape Measurements at Full-Scale, ME Thesis, Chalmers University Of Technology, Sweden.

Puddu P., Nurzia, F., Pistidda, A., Mura, A., 2006.Full Scale Investigation of One-Design Class Catamaran Sails.2nd High Performance Yacht Design Conference. Auckland, New Zealand.

Richards, P.J., Lasher, W., 2008. Wind Tunnel and CFD Modelling of Pressures on Downwind Sails, BBAA VI International Colloquium on Bluff Bodies Aerodynamics \& Applications, Milano, Italy.

Viola, I.M., 2009. Downwind Sail Aerodynamics: a CFD Investigation with High Grid Resolution, Ocean Engineering, 36 (12-13), 974-984.

Viola, I.M., Flay, R.G.J., 2009. Force and Pressure Investigation on Modern Asymmetric Spinnakers, International Journal of Small Craft Technology, pp. 31-40.

Viola, I.M., Flay, R.G.J. 2010a. Pressure Measurements on Full-Scale and Model Scale Upwind Sails, $17^{\text {th }}$ Australasian Fluid Mechanics Conference, Auckland.

Viola, I.M., Flay, R.G.J., 2010b. Full-scale pressure measurements on a Sparkman and Stephens 24-foot sailing yacht. Journal of Wind Engineering and Industrial Aerodynamics 98(12): 800-807.

Viola, I.M., Flay, R.G.J., 2011. Sail pressures from full-scale, wind-tunnel and numerical investigations. Journal of Ocean Engineering 38(16): 1733-1743.

Wright, A.M., Claughton, A.R., Paton, J., Lewis, R., 2010. Off-Wind Sail Performance Prediction and Optimisation, The Second International Conference on Innovation in High Performance Sailing Yachts, Lorient, France. 

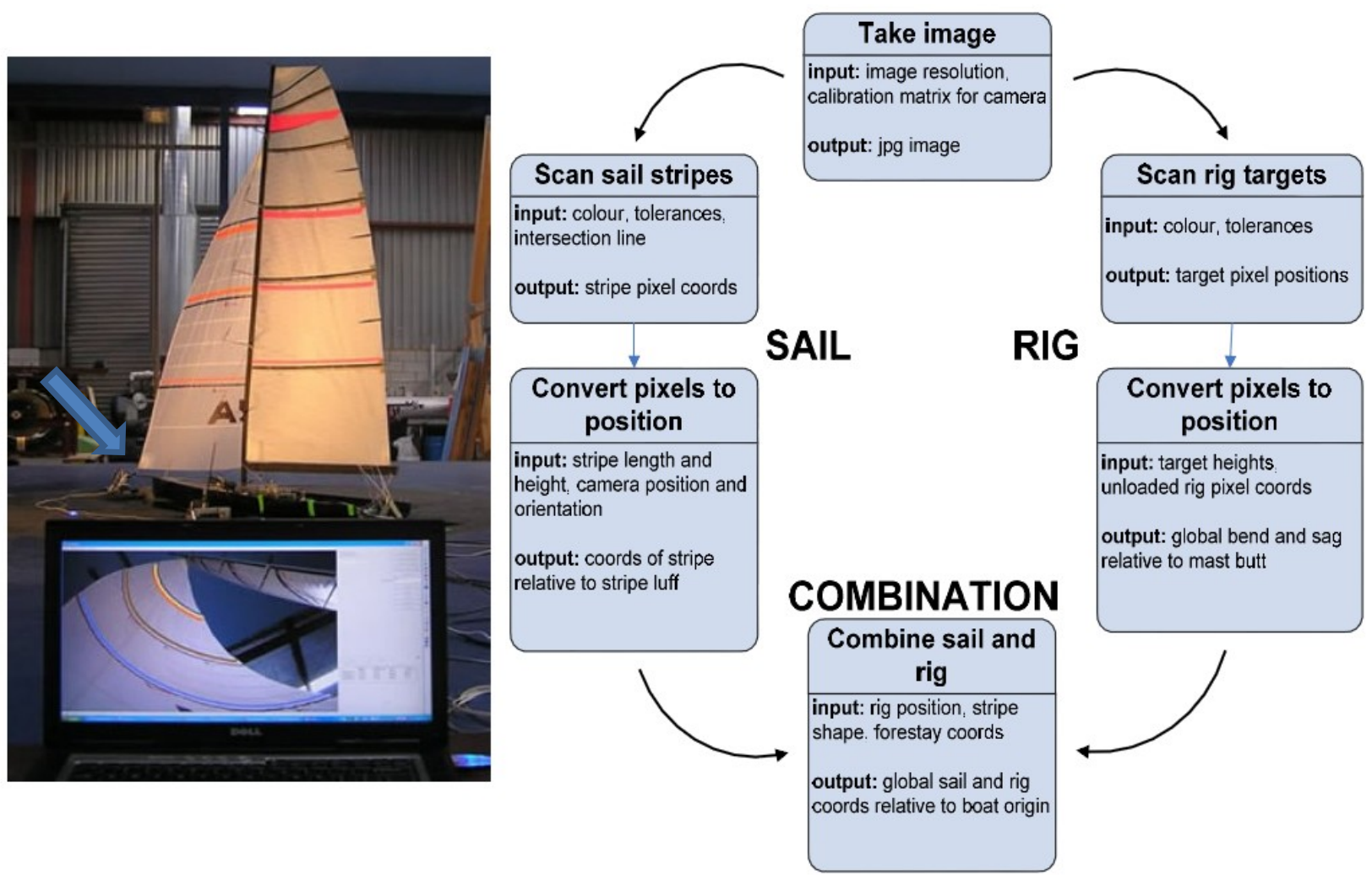

Figure 1: VSPARS system: screenshot of VSPARS operating in the wind tunnel and system flow chart
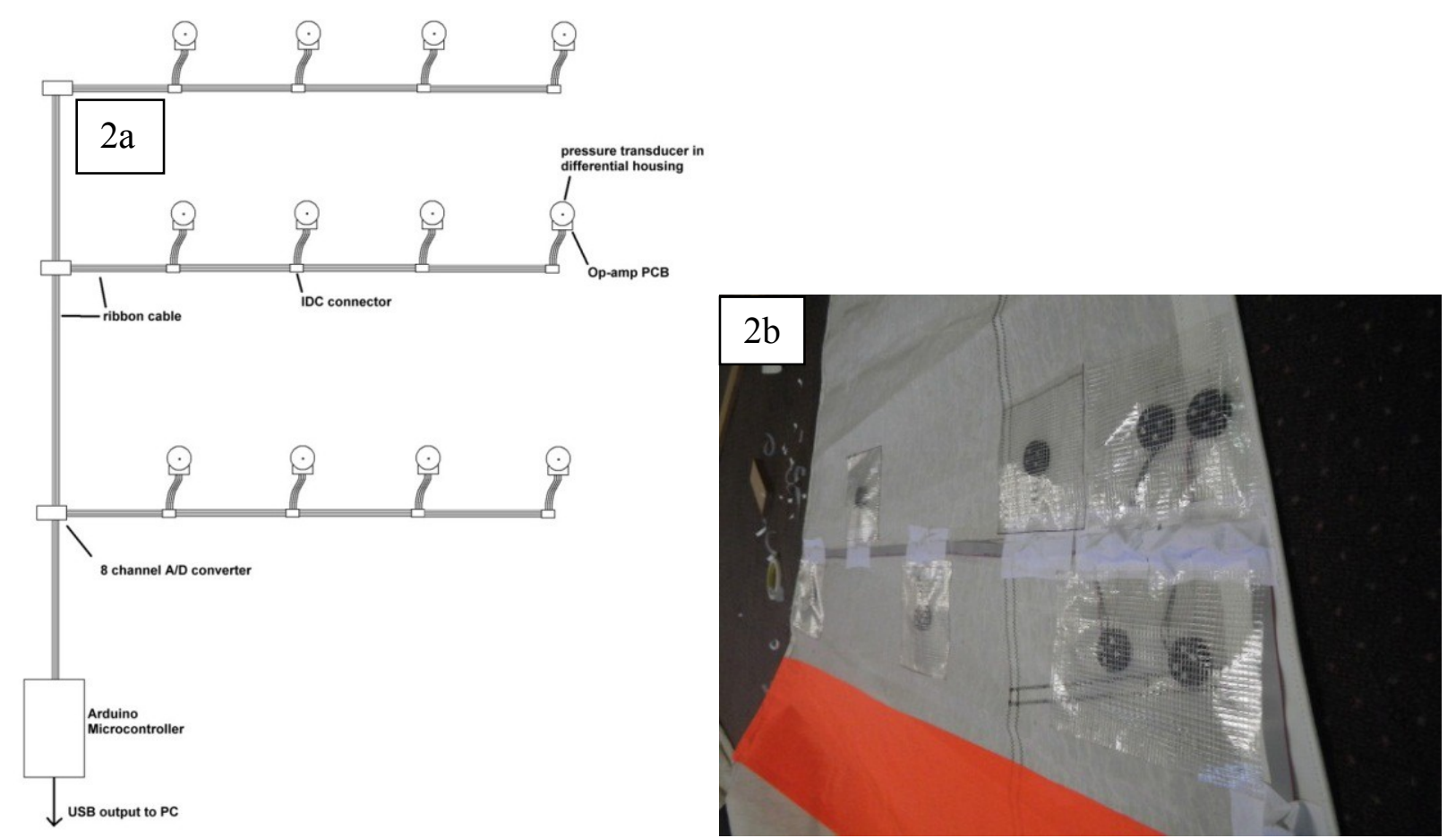

Figure 2:a) Generic layout of the YRU pressure system as applied to a sail; b) Example of application of pressure sensors on the sail showing the pockets containing the sensors 


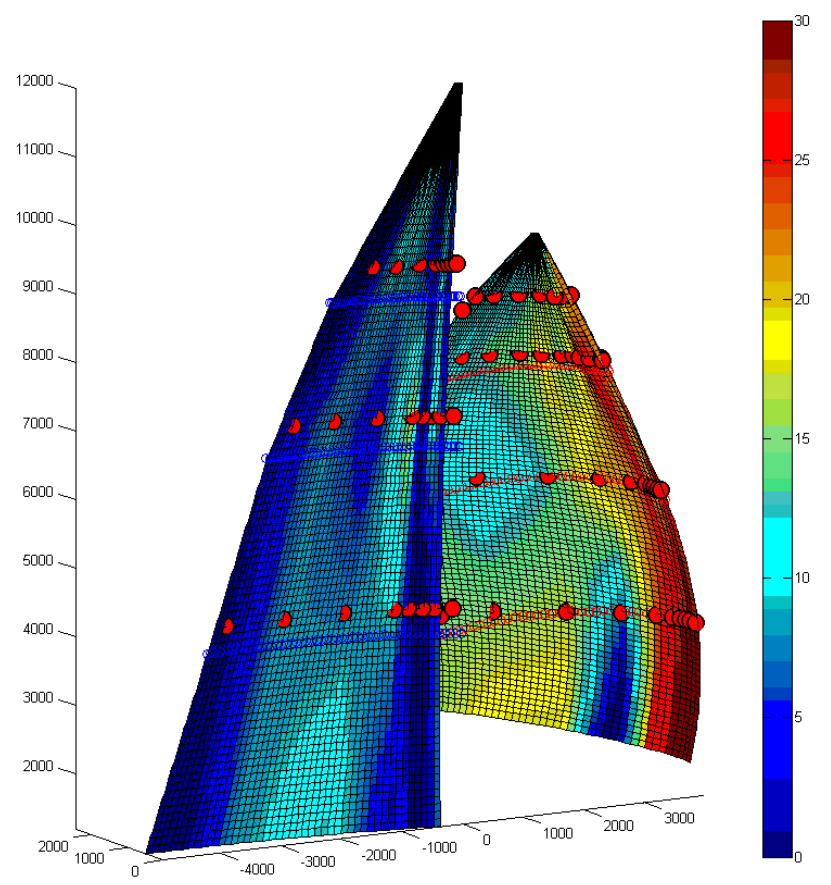

Figure 3: Pressure map distribution over the entire surfaces of the two sails.

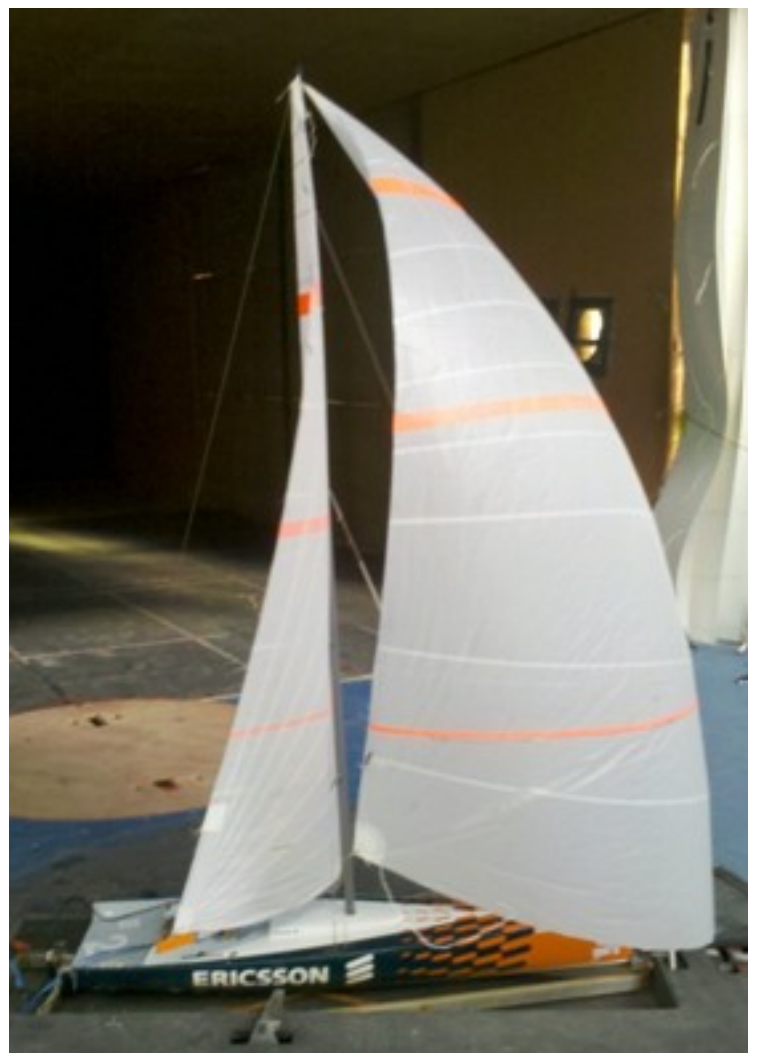

Figure 4: VO70 model scale yacht used for the FEPV wind tunnel validation where the VSPARS calculated sail positions were compared with physical measurements 


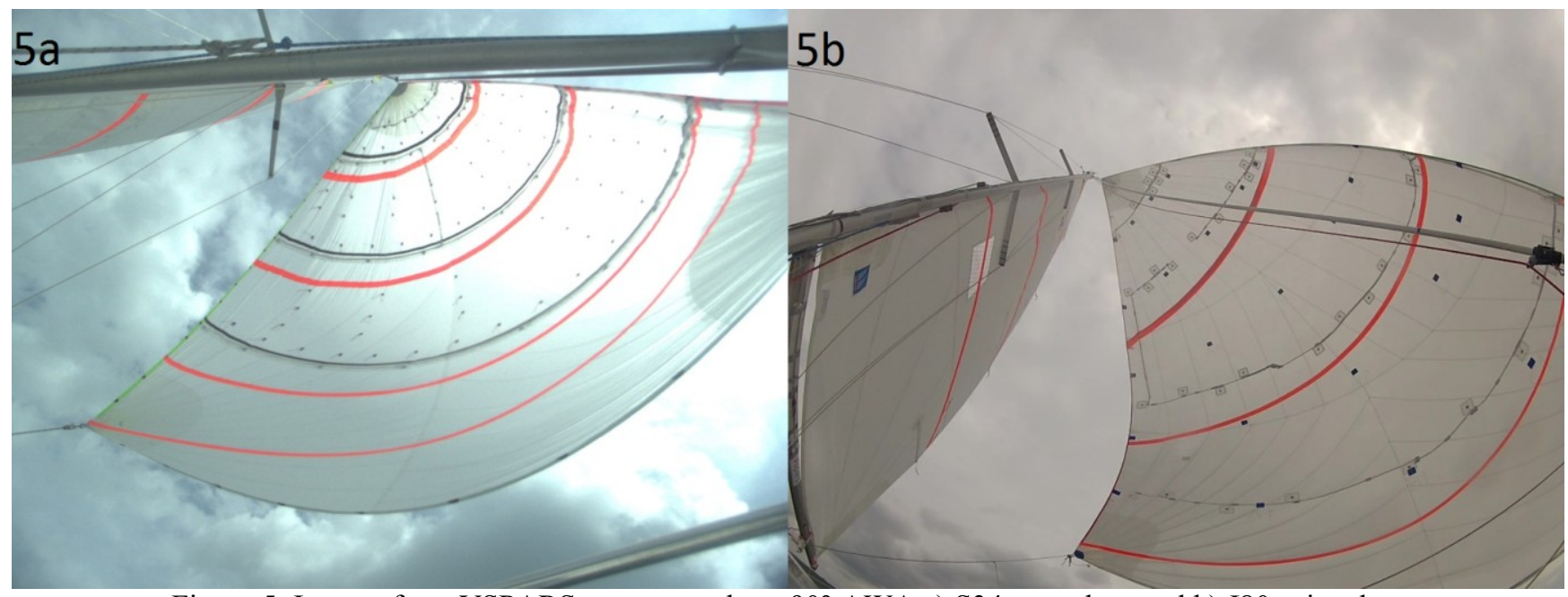

Figure 5: Images from VSPARS camera at about $90^{\circ} \mathrm{AWA}$ a) S34 gennaker, and b) J80 spinnaker.
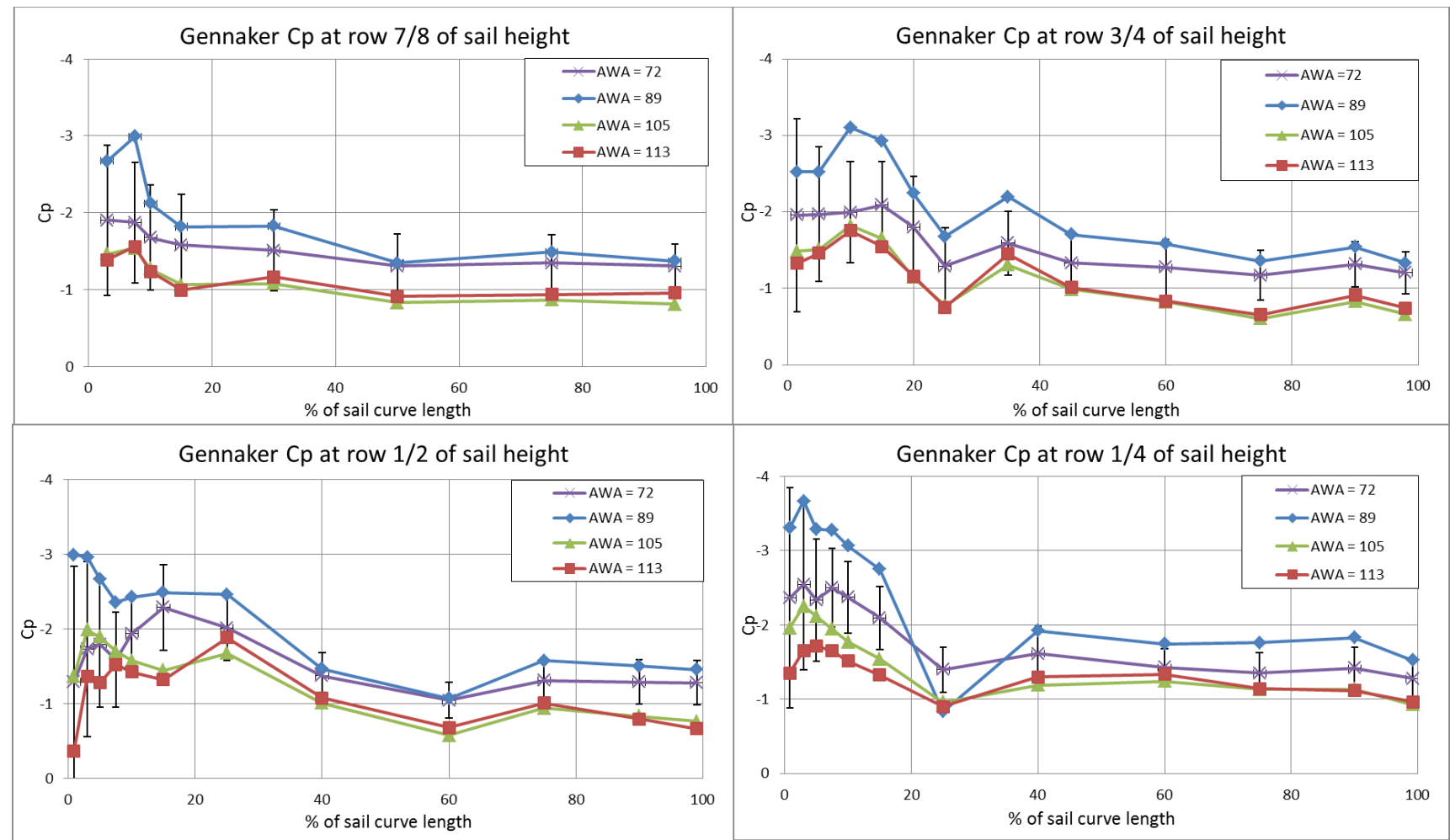

Figure 6: S34 gennaker pressure distributions for AWAs of $72^{\circ}, 89^{\circ}, 105^{\circ}$ and $113^{\circ}$ 


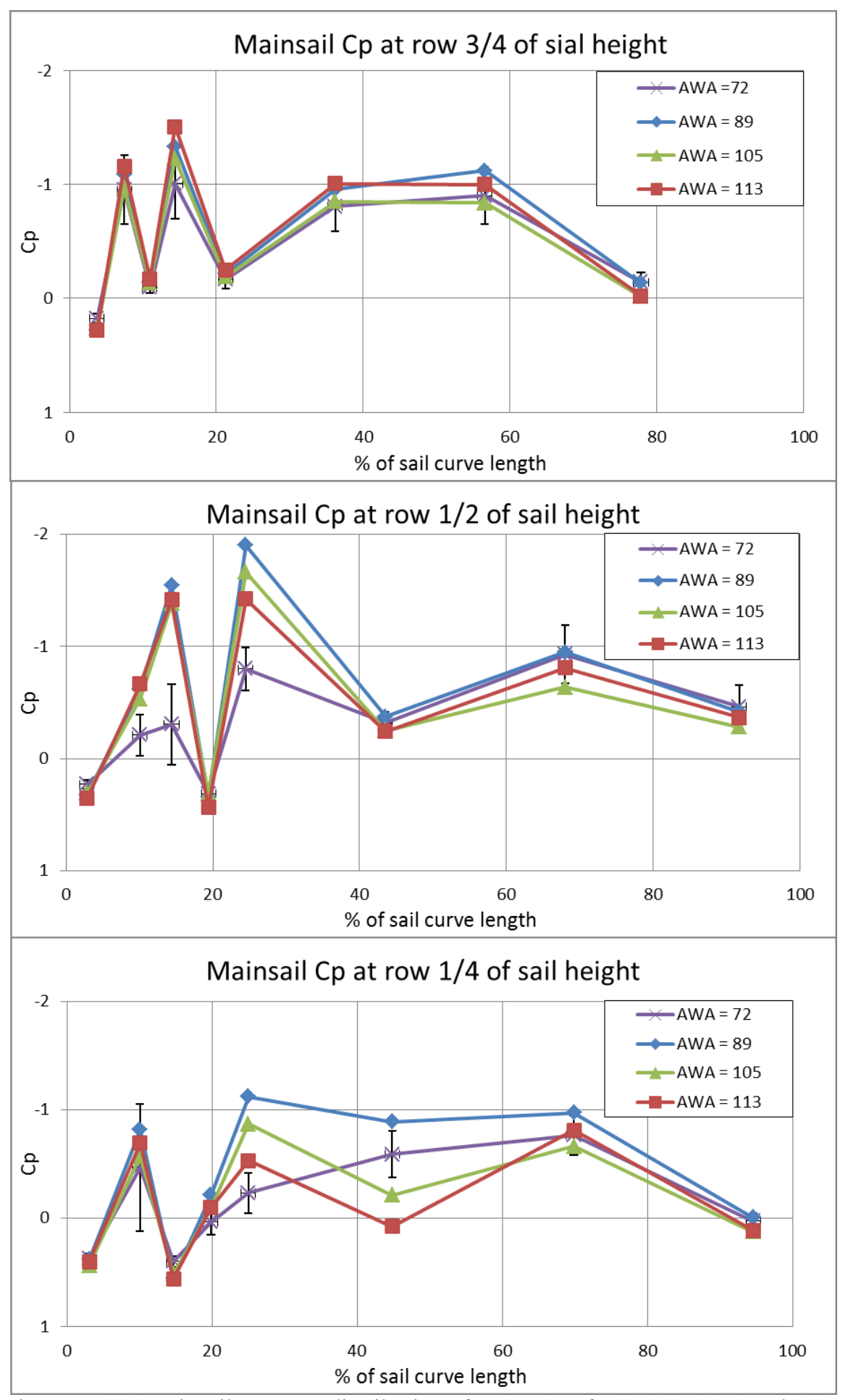

Figure 7: S34 mainsail pressure distributions for AWAs of $72^{\circ}, 89^{\circ}, 105^{\circ}$ and $113^{\circ}$ 


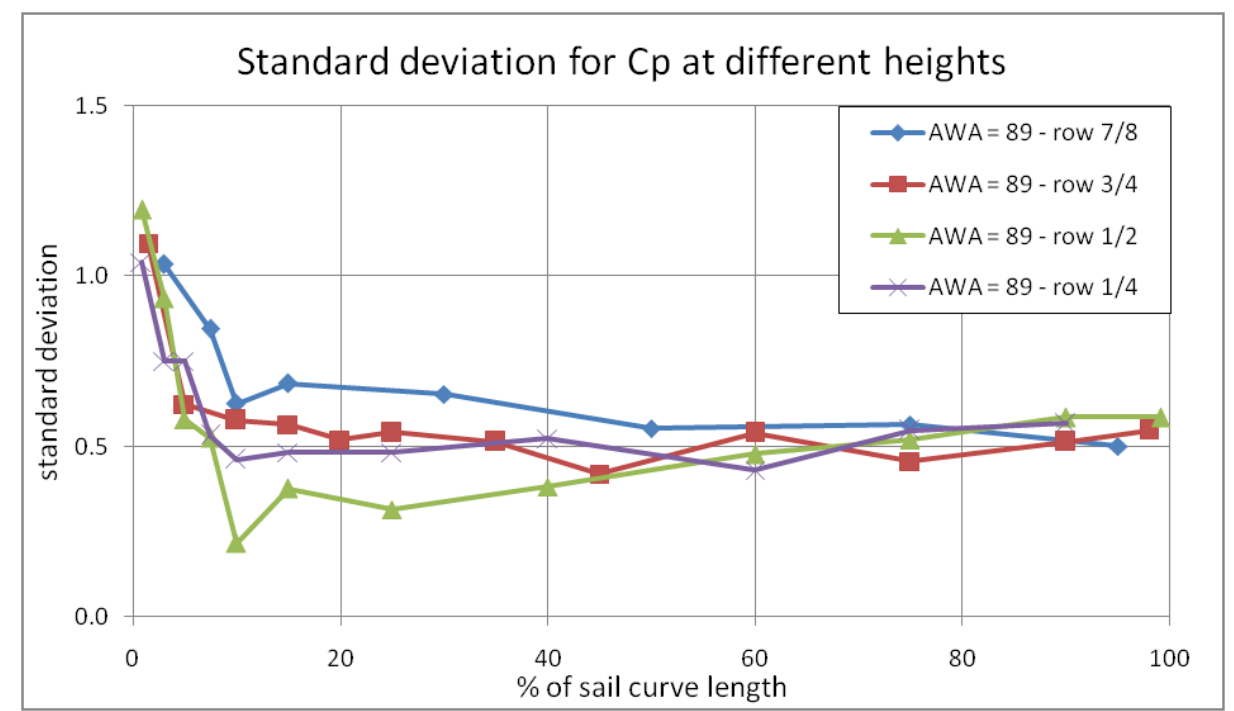

Figure 8: Stewart 34 gennaker standard deviation pressure coefficients for a run performed at AWA $=89^{\circ}$

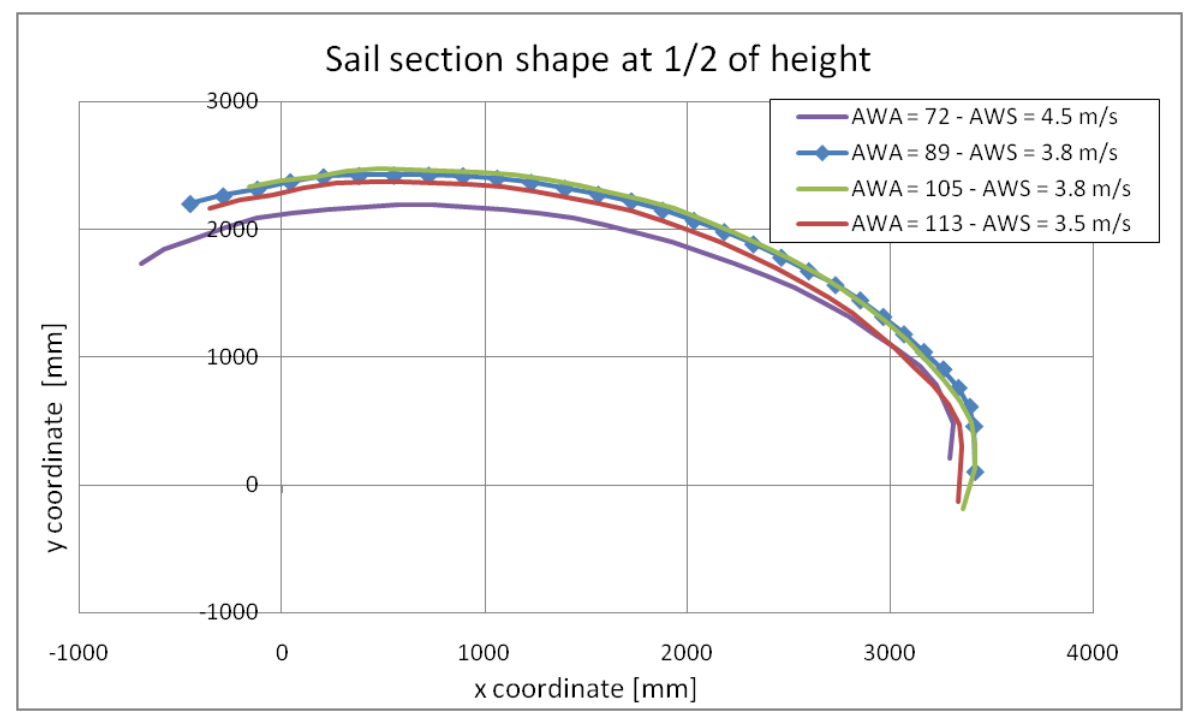

Figure 9: VSPARS recorded sail shape for the S34 gennaker stripe at $1 / 2$ height for a range of AWAs

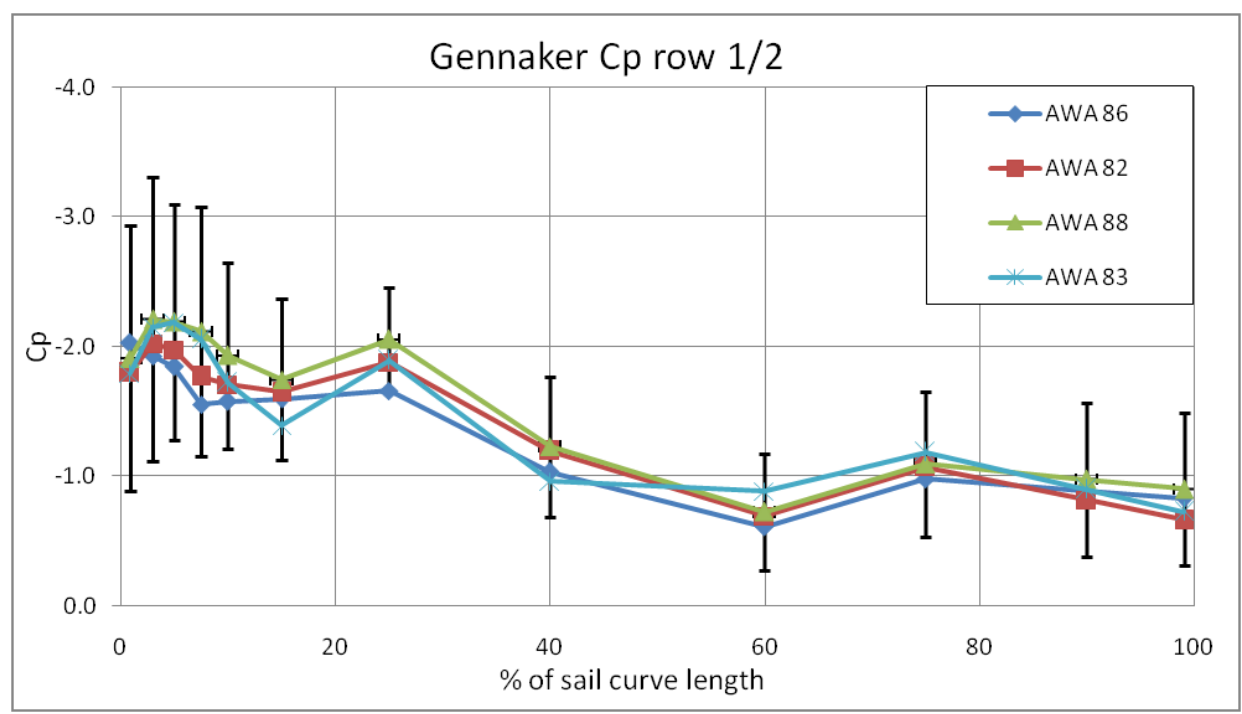

Figure 10: $\mathrm{Cp}$ at row 1/2 of sail height for several runs performed at similar AWAs for the S34 

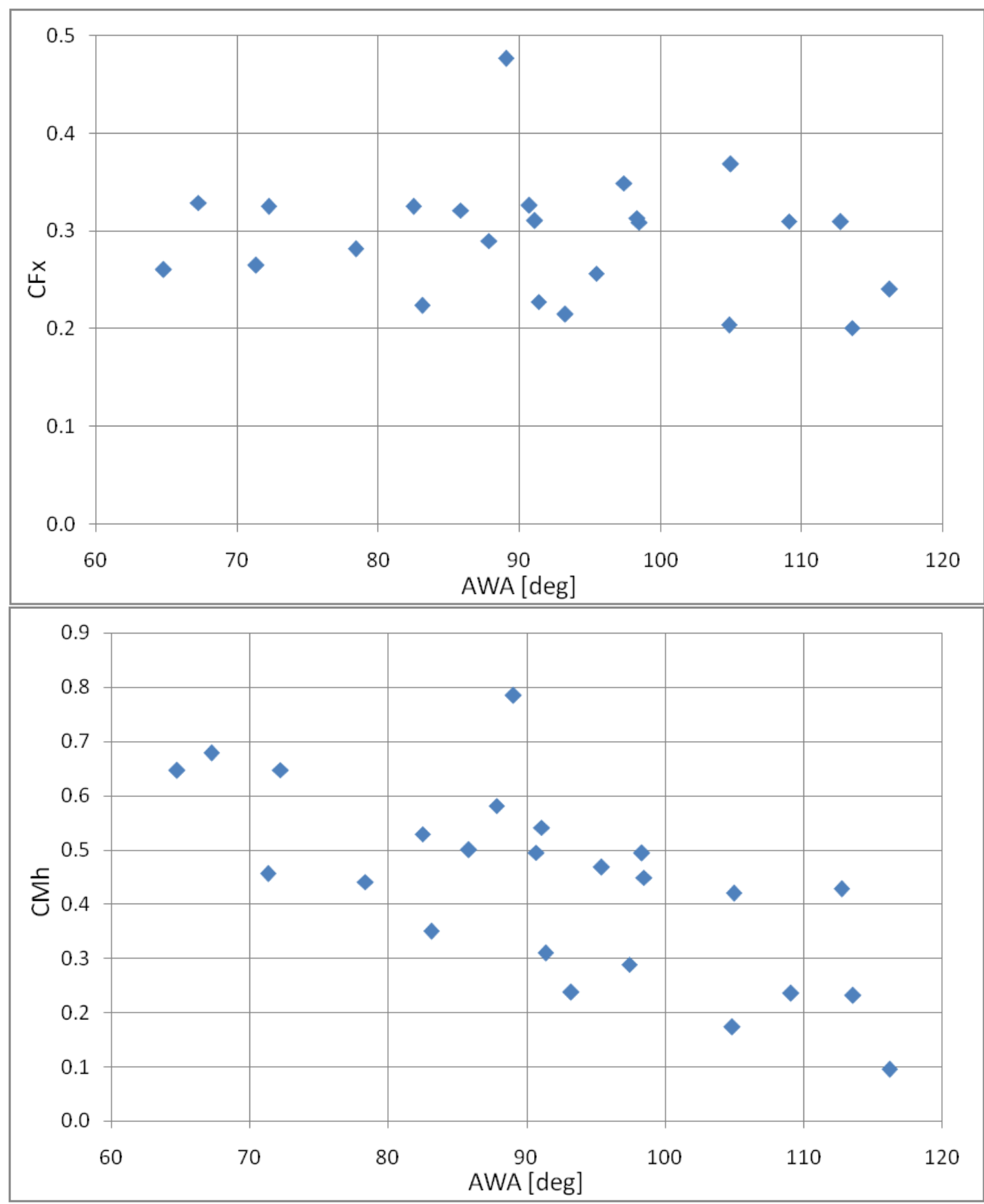

Figure 11: Total (gennaker plus mainsail) drive force and heeling moment coefficients vs. AWA for the S34 


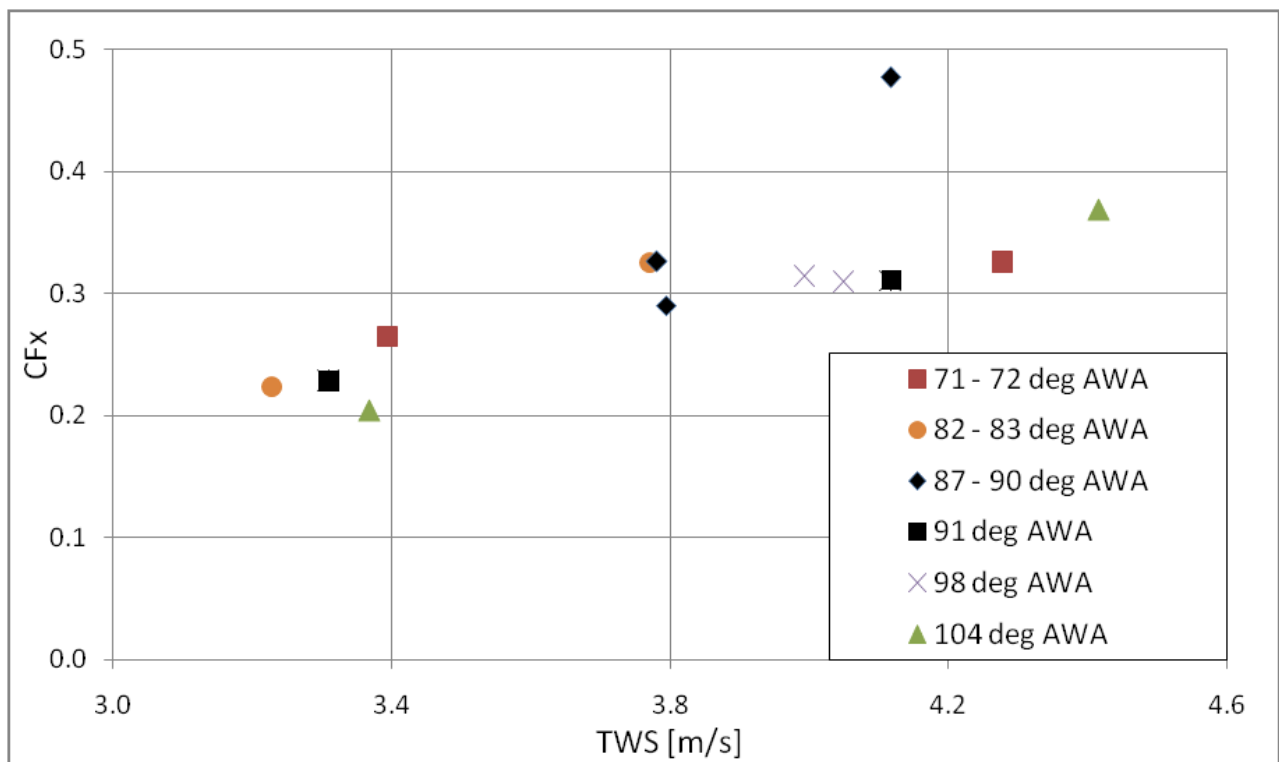

Figure 12: Total (gennaker plus mainsail) Stewart 34 drive force coefficients vs. true wind speed. 


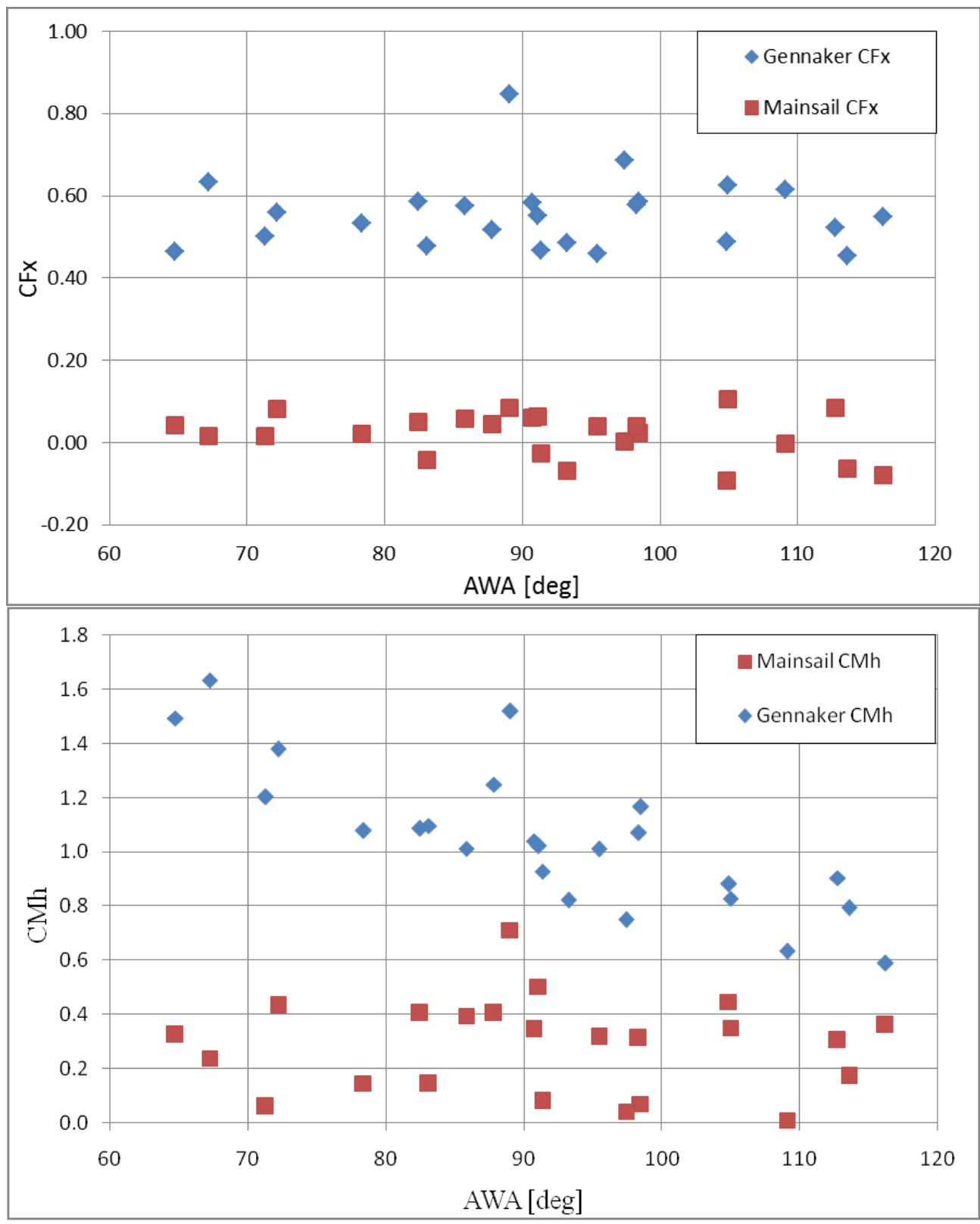

Figure 13: Drive force coefficients and heeling moment coefficients for S34 gennaker and mainsail separately vs. AWA 


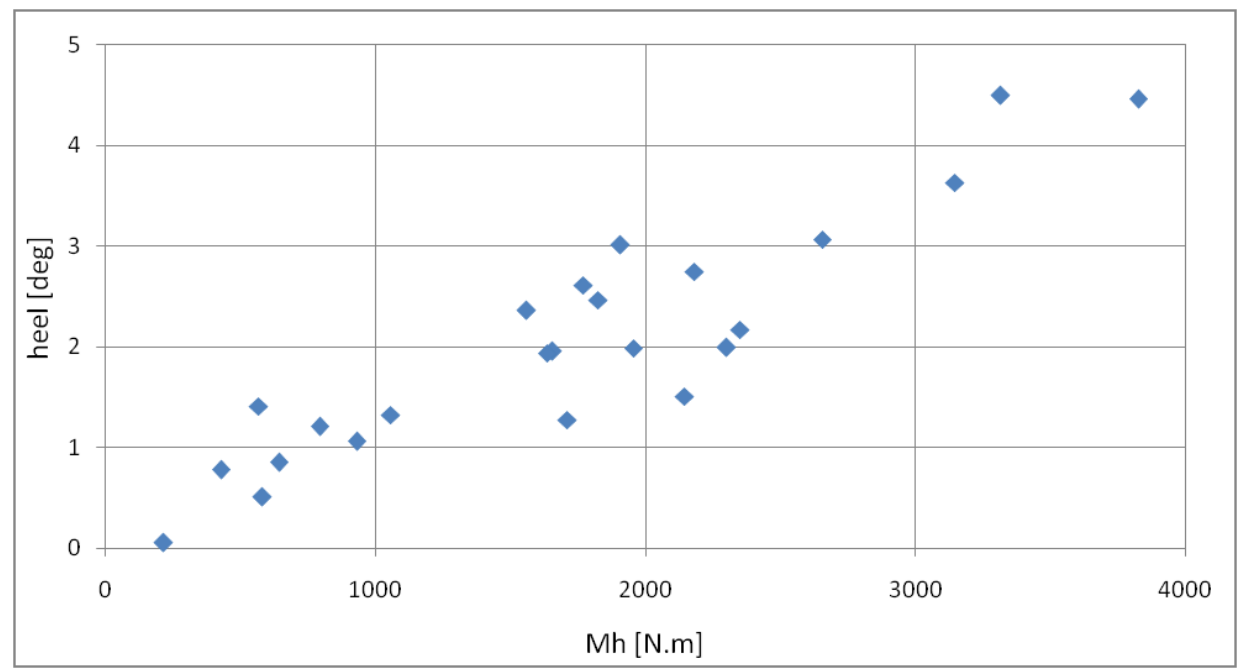

Figure 14: Heel angle vs. heeling moment for the S34.
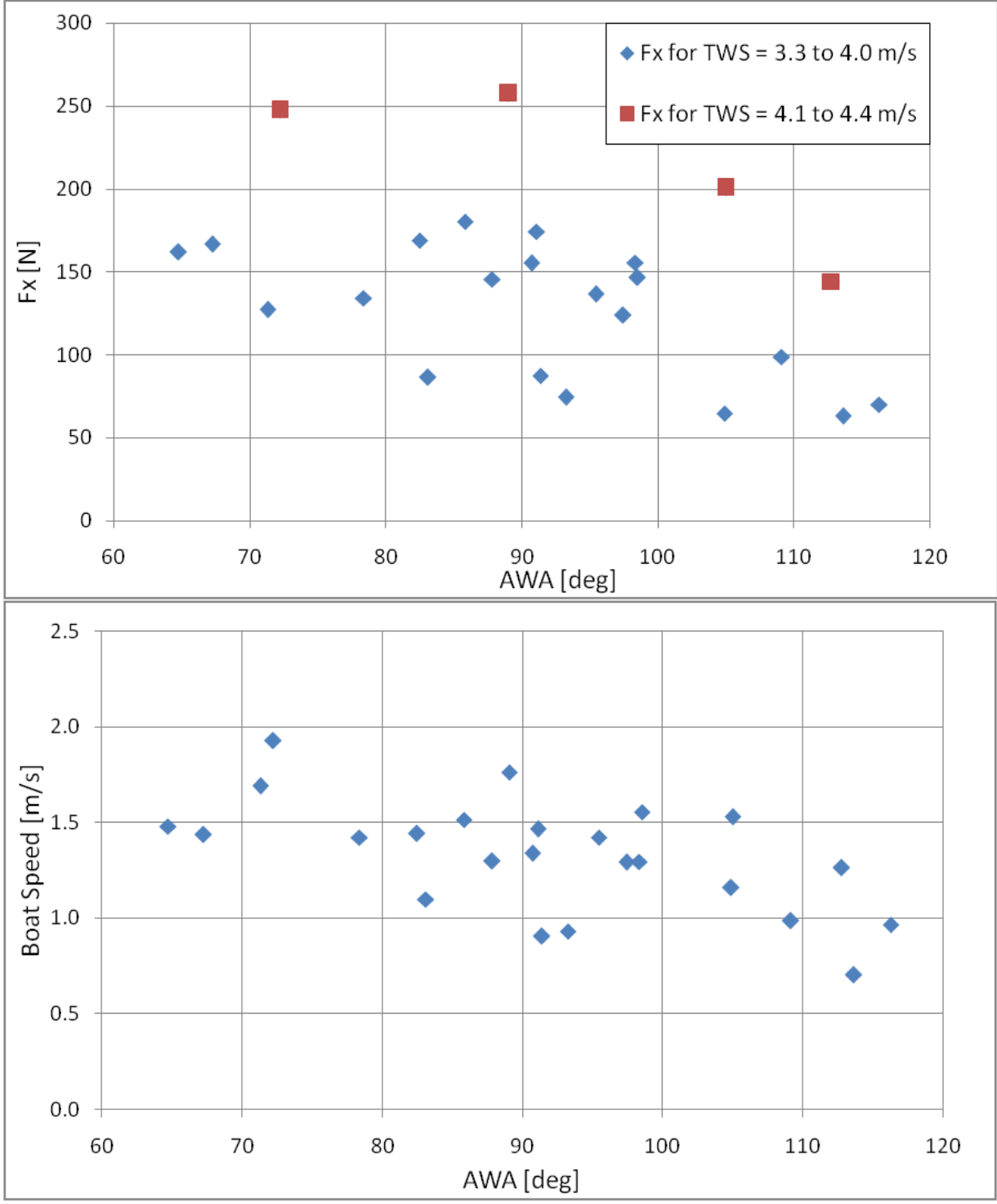

Figure 15: a) Total drive force vs. AWA, b) Boat speed vs. AWA for the S34. 


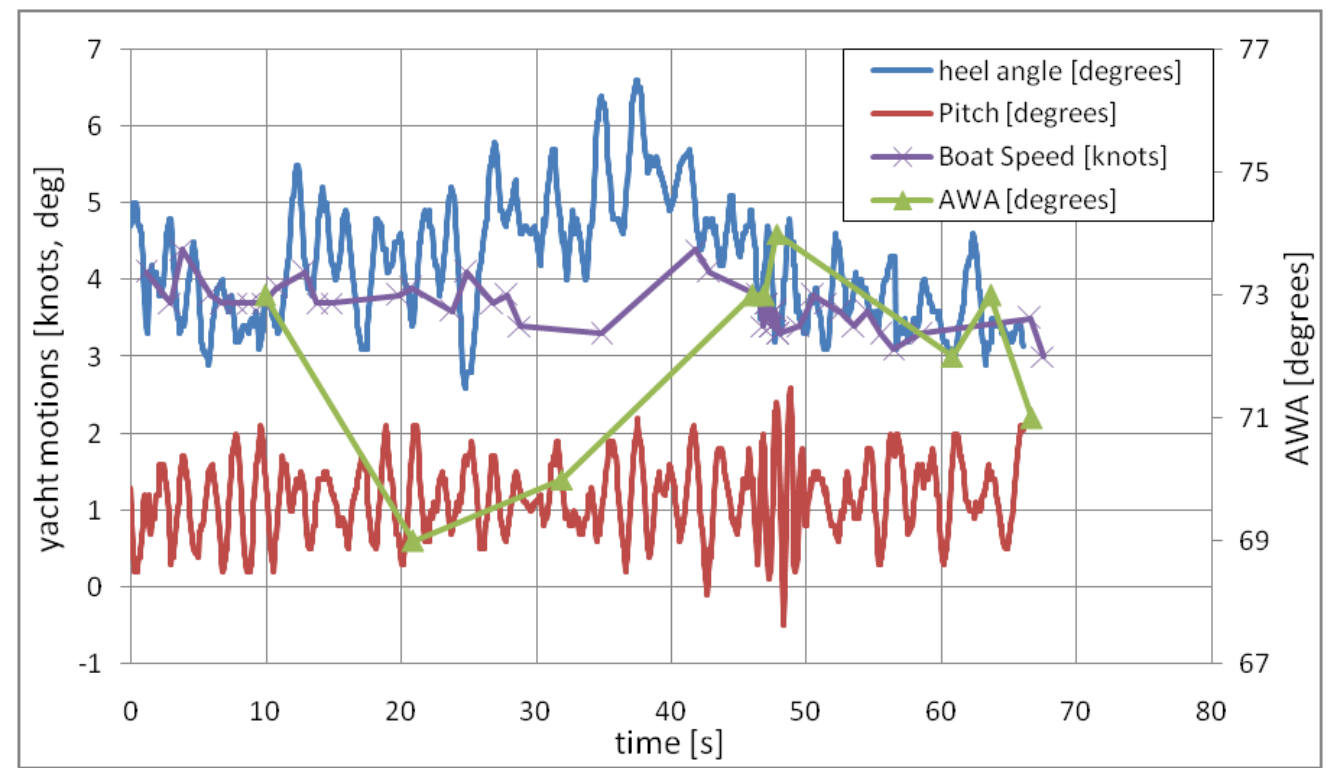

Figure 16: Stewart 34 test: extract of a typical signal time series

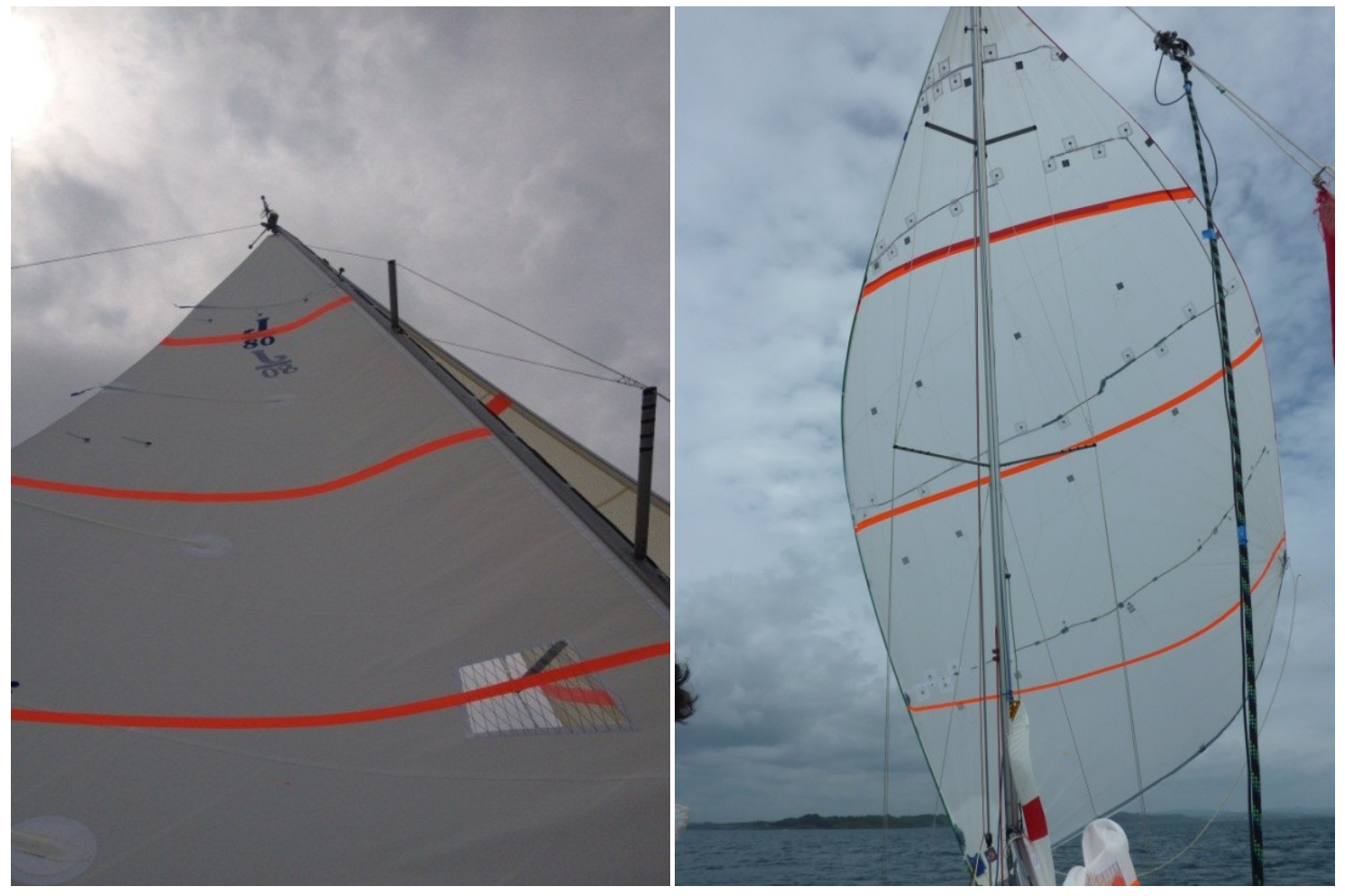

Fig. 17: Photographs of the J80 mainsail (left) and asymmetric spinnaker (right) 


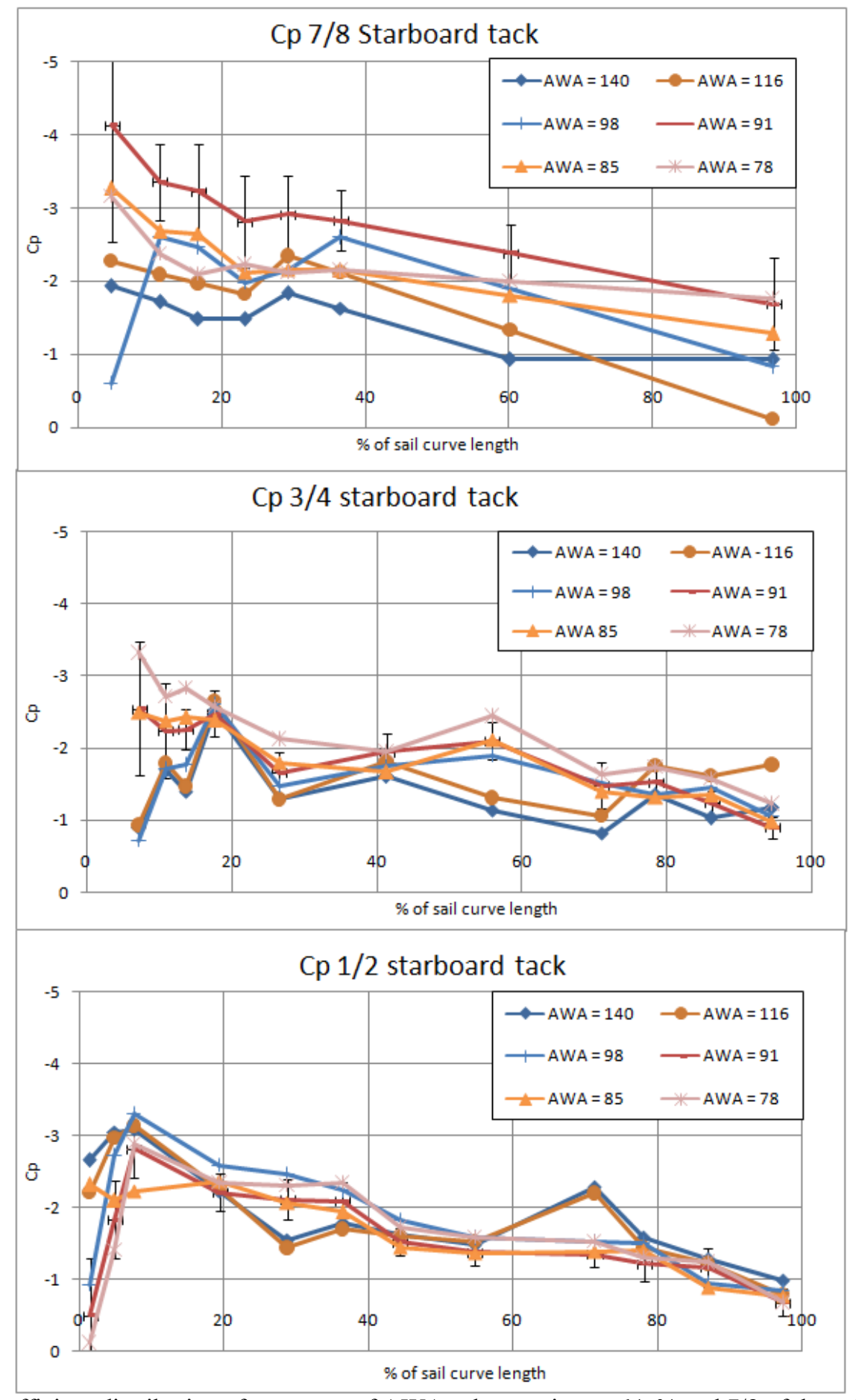

Figure 18: Pressure coefficient distributions for a range of AWAs along stripes at $1 / 2,3 / 4$ and $7 / 8$ of the sail height. Error bars represent $+/-1$ standard deviation 

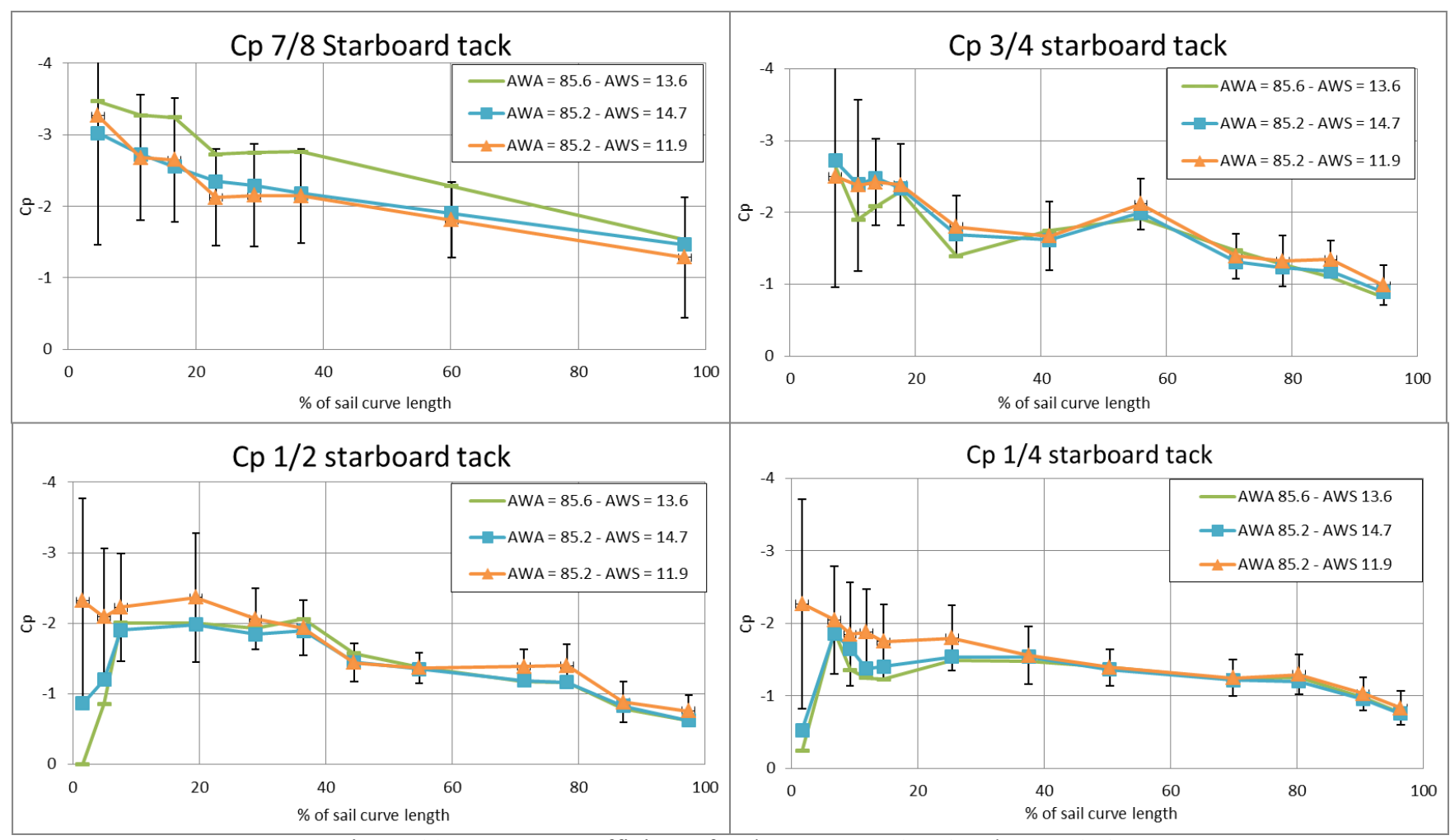

Figure 19: Pressure coefficients for three runs at AWAs close to $85^{\circ}$ 


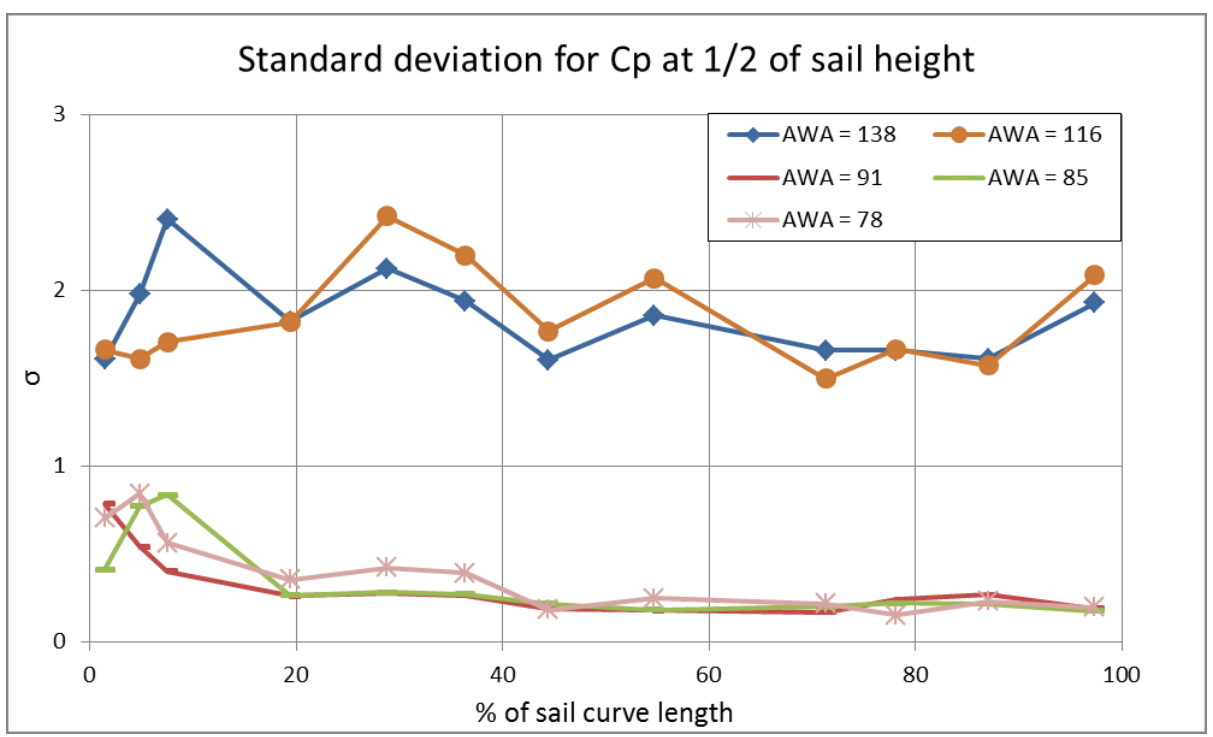

Figure 20: Standard deviation of pressure coefficients at several different AWAs

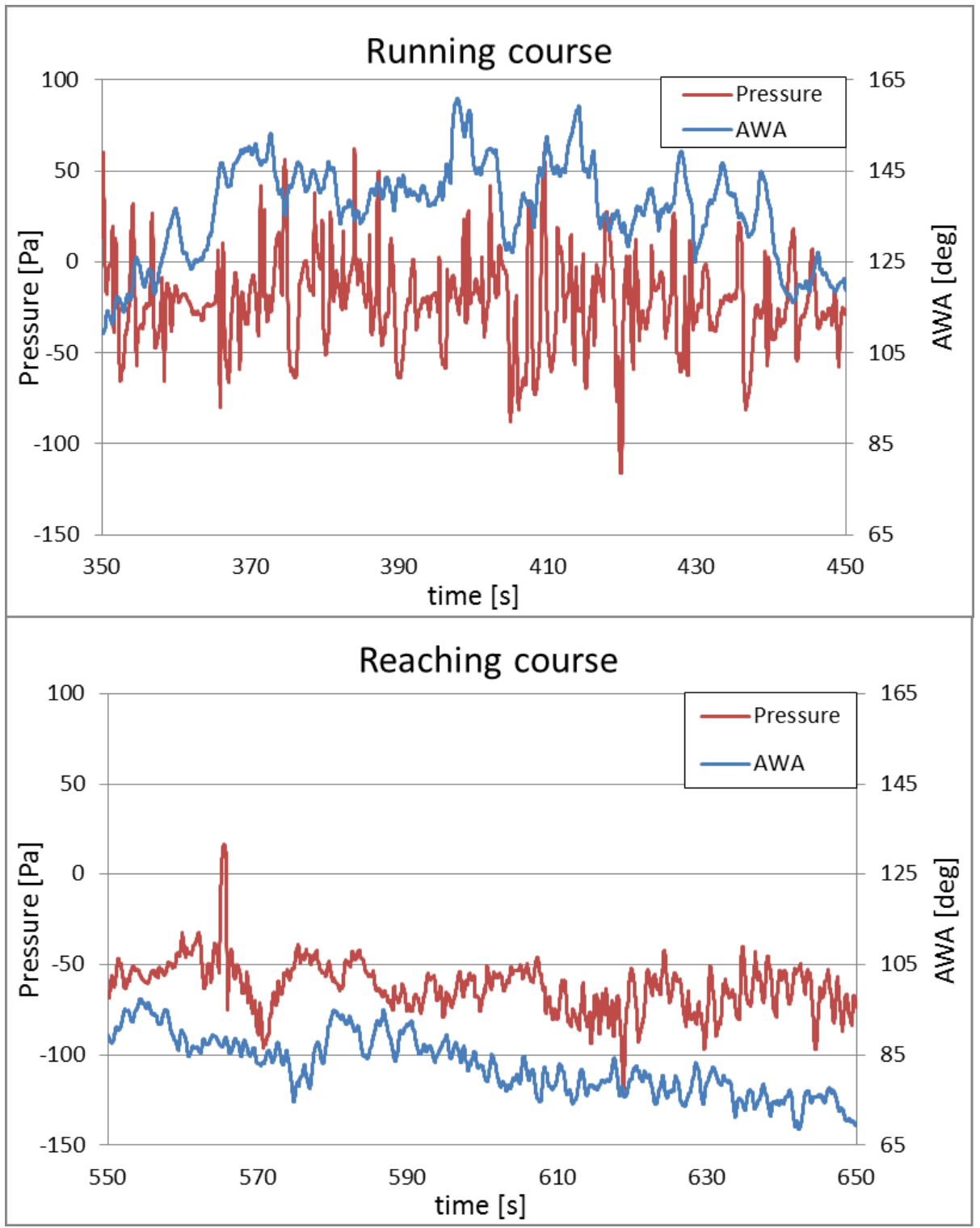


Figure 21: Pressure time series from second pressure sensor from luff at row $1 / 2$ at $10 \%$ of the curve

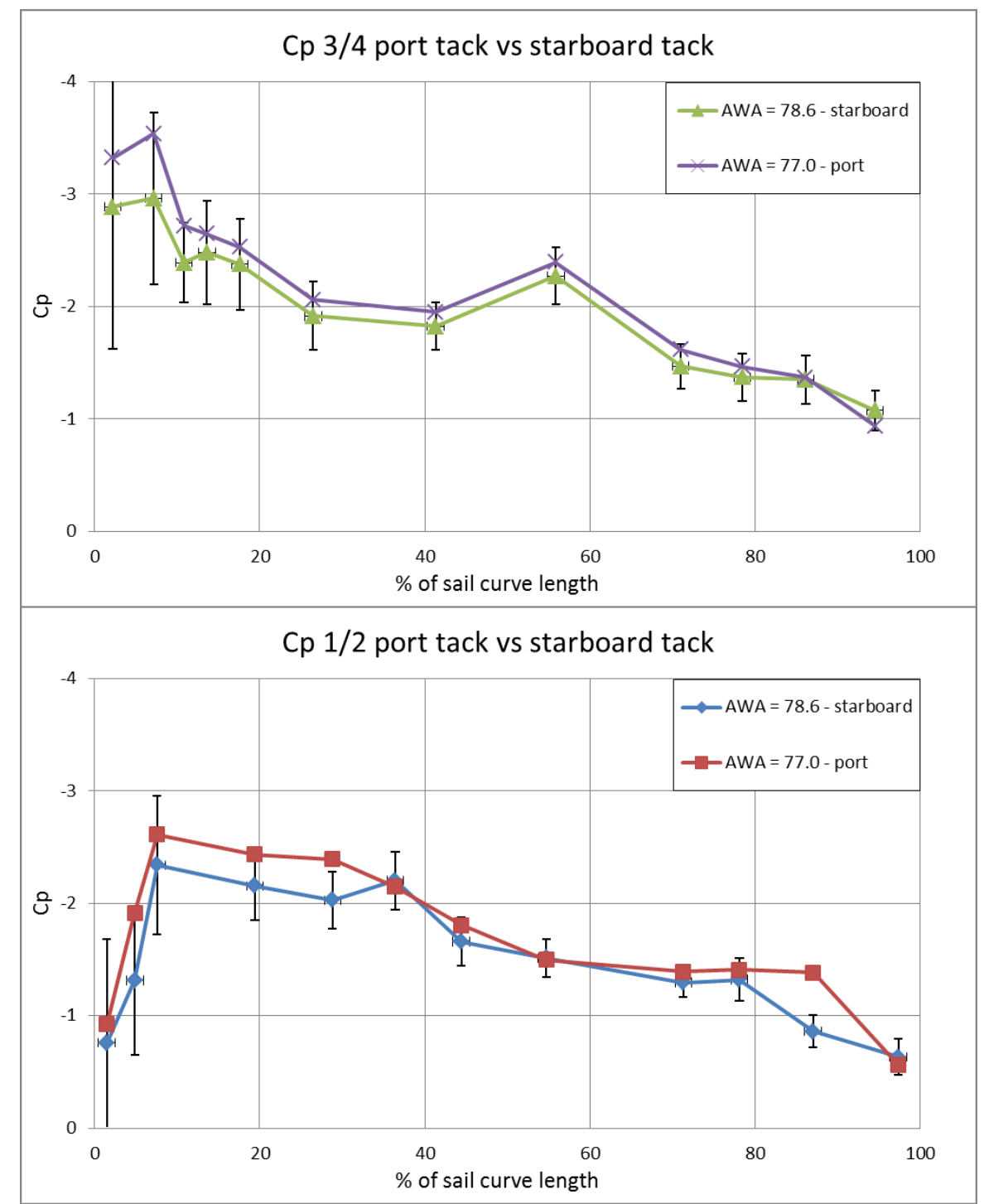

Figure 22: Pressure coefficient comparison between port and starboard tacks at different heights for an AWA close to $77^{\circ}$. 


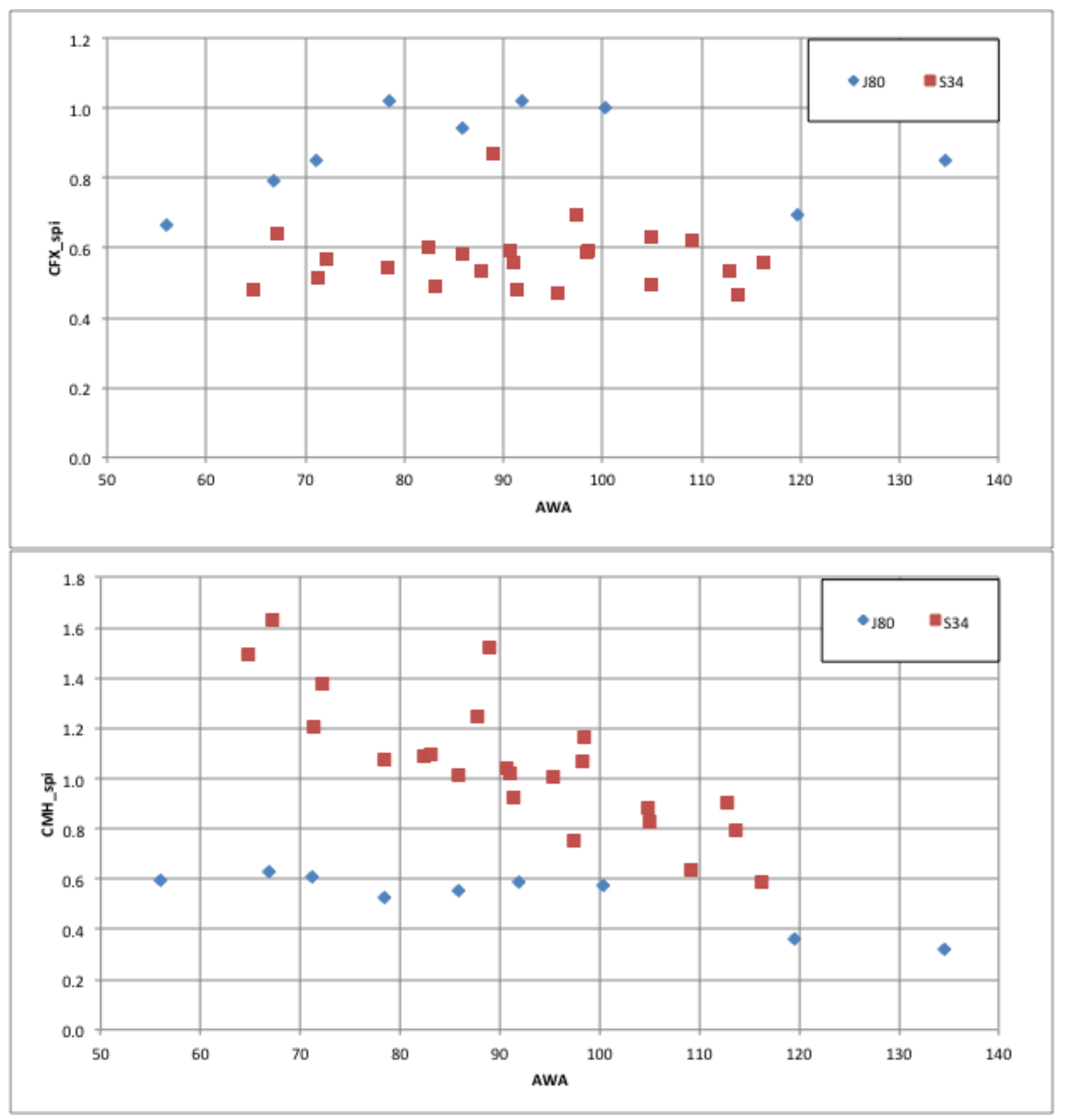

Figure 23: Drive force and heeling moment coefficients from J80 and S34 tests 


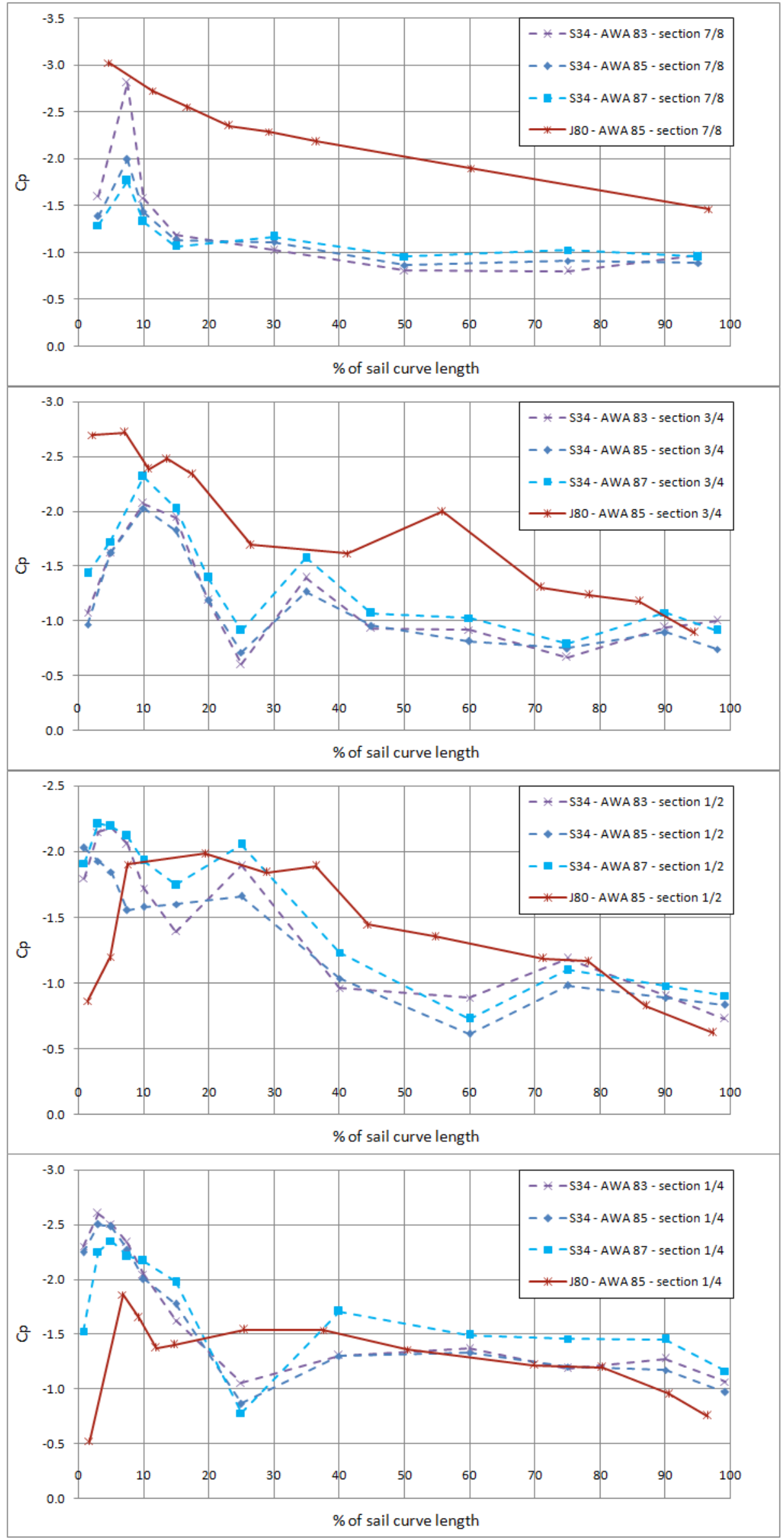

Figure 24: Comparison between S34 and J80 pressure coefficients from tests at about $85^{\circ}$ AWA 


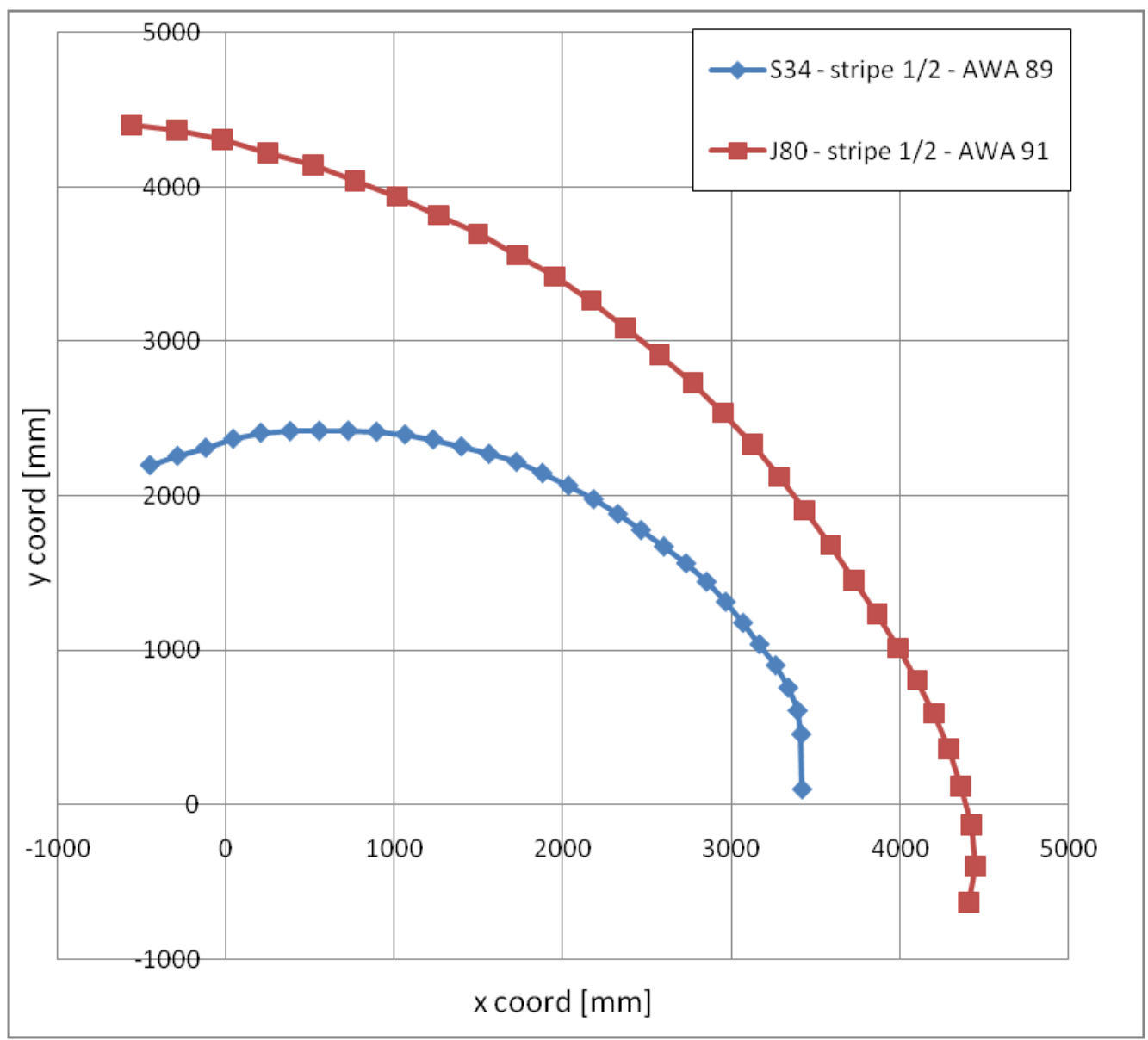

Figure 25: Sail shape at section $1 \frac{1}{2}$ as outputted from VSPARS 